\title{
REVIEW
}

Open Access

\section{Optical coherence tomography angiography (OCTA) as a new diagnostic tool in uveitis}

Vita L. S. Dingerkus ${ }^{1 *}$, Marion R. Munk², Max P. Brinkmann ${ }^{1}$, Florentina J. Freiberg ${ }^{1}$, Florian M. A. Heussen ${ }^{1}$, Stephan Kinzl ${ }^{1}$, Sandra Lortz ${ }^{1}$, Selim Orgül ${ }^{1}$ and Matthias Becker ${ }^{1,3}$

\begin{abstract}
Background: The broad spectrum of uveitis disorders requires a multimodal imaging approach in the daily practice of an ophthalmologist. As inflammatory conditions, they have in common an alteration in leukocyte migration. In this context, optical coherence tomography angiography (OCTA) might be of great value for diagnosing or following up patients with these disorders. To date, OCTA has rather been used as an additional tool besides the well-established diagnostic imaging tools, but its complementary diagnostic features become increasingly relevant, to follow disease activity and treatment response and for the understanding of pathomechanisms of various uveitis types.

This review summarizes the possible applications of OCTA and its advantages and disadvantages as opposed to dyebased angiographies in uveitic diseases.

Main body: Hitherto gold standards in the diagnostic workup of posterior or intermediate uveitis have been angiography on a dye-based method, which is fluorescein or indocyanine green. It gives information about the status of the blood-retinal barrier and the retinal and choroidal vasculature by visualizing diffuse leakage as a state of inflammation or complications as an ischemia or choroidal neovascularization. As noninvasive methods, fundus autofluorescence depicts the status of metabolic activity of the retinal pigment epithelium and OCT or enhanced depth imaging OCT, respectively, as a depth-resolving imaging method can supply additional information.

OCTA as a non-invasive, depth-resolution imaging tool of retinal and choroidal vessels adds detailed qualitative and quantitative information of the status of retinal and choroidal vessels and bridges the gap between the mentioned conventional diagnostic tools used in uveitis.

It is important, though, to be aware of its limitations, such as its susceptibility to motion artifacts, limited comparability among different devices, and restricted contribution of information regarding the grade of disease activity.

Conclusion: OCTA as a non-invasive, depth-resolution imaging tool can give qualitative and quantitative information about the status of retinal and choroidal vessels, but also has certain limitations. Employing OCTA as a complementary rather than exclusive tool, it can give important additional information about the macro- and microvasculature under inflammatory circumstances. Thereby, it also contributes to the understanding of the pathophysiology of various uveitis entities.
\end{abstract}

Keywords: Optical coherence tomography angiography, Fluorescein angiography, Indocyanine angiography, Uveitis, Diagnostic tools

\footnotetext{
* Correspondence: vita.dingerkus@zuerich.ch

'Department of Ophthalmology, City Hospital Triemli, Birmensdorferstrasse

497, CH-8063 Zürich, Switzerland

Full list of author information is available at the end of the article
} 


\section{Background}

Optical coherence tomography angiography (OCTA) is a new diagnostic tool which was developed as an extended technique of already existing imaging module. Optical coherence tomography (OCT) produces a depth-resolved evaluation of the reflectance data from tissues. OCT thereby allows a three-dimensional image of the retina, which is also the case for OCTA [1,2]. OCTA employs speckle or phase variance or amplitude decorrelation for detection of motion contrast and imaging of blood flow of different layers of the retina and choroid. Stationary tissue, in contrast, does not lead to a signal in OCTA, whereas changing structures, as is the case in blood flow, can be detected via repeated images over the same focus of interest [3]. In contrast to dye-based angiographies, OCTA is non-invasive, non-hazardous, and easier and faster to apply. This makes OCTA very interesting, especially in the field of retinology and uveitis.

In uveitis, various vascular abnormalities can be seen due to different underlying pathomechanisms, leading to ischemia, neovascularization, or retinal and/or choroidal vasculitis. Up to now, most important diagnostic tools for vascular pathologies are fluorescein angiography (FA) and indocyanine green angiography (ICGA), both requiring an infusion of dye, thereby being invasive and holding the risk of side effects [4]. In various conditions, such as known allergy against the substances, renal impairment, or pregnancy, the use of dye should be avoided or only used with caution. Furthermore, these techniques are limited when it comes to the warrant of further evaluation of different vascular layers than only distinction of retinal and choroidal vasculature $[5,6]$. Moreover, in FA and ICGA images, the visual accessibility of vessels can be limited and hampered by dye leakage. Non-invasive fundus autofluorescence images (FAF), OCT, and enhanced depth imaging-OCT (EDI-OCT) can supply additional information about the structures of concern, but do not show details of the vascular structure or blood flow. OCTA, in contrast, can visualize the different layers more independently from surrounding leakage of fluorescein, than FA $[7,8]$. However, the quality of OCTA images can also be reduced due to an overlying obscuration like in FA, for example, in cases of vasculitis, predominantly by vitritis or bleedings.

Finally, as the central vision might be affected, the assessment of OCTA images can become quite difficult [9].

Nevertheless, OCTA might be an additional tool in a multimodal imaging approach to provide a better understanding of various uveitis types; however, because of its complexity and susceptibility to artifacts, it requires careful scrutiny during interpretation [10].
This review aims to give an overview on new knowledge gained so far about the applicability and limitations of OCTA in different forms of uveitis. Advantages or disadvantages, when it comes to comparison of OCTA and dye-based angiographies, will be highlighted. It emphasizes the use of OCTA in posterior uveitis and white dot syndromes, as it is in these entities, that most studies and reports have been published. However, it must be mentioned that a major proportion of publications on OCTA and uveitis is based on case reports or case series.

\section{About fluorescein angiography}

Fluorescein sodium is a dye containing fluorescein molecules of $354 \mathrm{Da}$ which is injected intravenously to obtain an image of the vascular status of the retina. Under inflammatory conditions, the unbound part (ca. 20\%) can leak out of retinal vessels, even the smallest ones, thereby making it the first-line-investigation for retinal vasculitis, capillary leakage, and edema, either diffuse or focal, or for identification of choroidal neovascularization [11-15].

Nowadays, the gold standard for diagnosing macular edema (ME) is OCT, as it is, in contrast to fluorescein angiography (FA), noninvasive, faster, and easier applicable. However, it should be considered to be complementary to FA, as the latter may show leakage when retinal thickening is not verifiable [16]. Thus, FA remains the most sensitive modality to detect retinal vessel inflammation and allows monitoring the process of the disease or response to therapy. In particular, widefield FA is of interest in uveitis because it can detect peripheral vascular leakage, ischemic conditions, or nonperfusion and is highly specific and sensitive for clinical disease activity $[17,18]$. Considering uveitis, FA has become an essential diagnostic tool for intermediate and posterior uveitis. It is important for anterior uveitis in case of co-existing macular edema. However, FA has not been established as an essential imaging tool for anterior vascular affection although it may detect subtle peripheral and optic nerve head leakage in active anterior uveitis as well [19].

In addition to the need of an invasive injection of dye to the patient, there are risks of side effects. Besides the risk of local complications such as tissue necrosis, the risk of general side effects, reaching from moderate nausea to severe allergic reaction, needs to be taken into account [4]. One major disadvantage in terms of image resolution is its limitation in unveiling the morphological details of vessels and their anatomical layers, especially when there is leakage [20, 21]. Moreover, deeper choroidal vessels cannot be evaluated properly, as the choriocapillaris is 
fenestrated and naturally leaks dye, and, thus, its own vascular details and the larger choroidal vessels are obscured [20].

\section{About indocyanine angiography}

While fluorescein is a rather small molecule and mainly unbound, indocyanine green (ICG) is mostly (98\%) bound to plasma proteins. Therefore, it is mainly used to evaluate the choroidal vasculature, as it remains in the vessels, unlike fluorescein, whose wastage from the intravasal space makes appraisal of the choroidal vascular morphology impossible [20].

ICGA thus plays an important role in diagnosing diseases including damage of the retinal pigment epithelium (RPE) and serous detachment [20, 22], and has been involved in diagnostic criteria of inflammatory diseases, mainly those affecting or originating from the choroid, such as the "white dot syndromes" (such as multiple evanescent white dot syndrome (MEWDS), acute posterior multifocal placoid pigmentepitheliopathy (APMPPE), multifocal choroiditis and panuveitis (MCP) and punctate inner choriodopathy (PIC), serpiginous choroiditis, and birdshot chorioretinopathy (BSR)), or granulomatous inflammations such as sarcoidosis and tuberculosis as well as other infectious diseases such as syphilis or toxoplasmosis [23].

Considering certain ICGA patterns, one can differentiate between choriocapillaritis (seen in white dot syndromes) and stromal choroiditis, mostly granulomatous [24].

In choriocapillaritis, hypocyanescence on ICGA can either be a sign of hypoperfusion of the choroid, appearing in a patchy or geographic pattern, or an impairment of the filling of the choroid with the dye due to space-occupying lesions [24]. In the convalescent phase, this hypocyanescence may diminish or remain in case of chorioretinal atrophy (corresponding to window defect on FA) [24]. Progressing lesions such as in serpiginous choroiditis may show diffuse hypercyanescence at the edges of lesions [24].

Stromal choroiditis can be full- and partial thickness inflammation (mostly granulomata). It can either reflect a choroid targeting disease or be part of a systemic condition, in which case the hypocyanescent spots are distributed less regularly [23]. For example, in the case of birdshot chorioretinopathy, Vogt-Koyanagi-Harada disease and sympathetic ophthalmia hypocyanescent dots are evenly distributed, whereas in sarcoidosis, those spots appear in a more irregular pattern; both remaining hypocyanescent till the late phase, unless there is only partial thickness of the choroid affected, in which case it would become isocyanescent, because the choriocapillaris is not affected [23]. Late hypercyanescent spots surrounding those dark spots are a sign of surrounding larger choroidal inflamed vessels [23].

Furthermore, hypocyanescence may be a sign of diseased RPE, as a result of reduced indocyanine green uptake by the retinal pigment epithelium, which is important for co-interpretation of OCTA and ICGA, especially in diseases, where the question rises, whether the RPE or the choroid is the primary focus of inflammation, as described below [21, 25].

Just as in FA, interpretation and performance in ICGA are limited to its two-dimensionality, the need of injection, and the risk of side effects [26].

\section{About optical coherence tomography angiography}

After OCT had fundamentally changed the diagnostic approach in ophthalmology over the last two decades, optical coherence tomography angiography (OCTA) has been introduced into the field of ophthalmology only a few years ago. The technique of OCTA is based on the comparison of repeatedly assessed OCT scans of the same region, imaging the change between images, which is, in case of OCTA, the movement of blood in the vasculature of the eye. This is important to consider, because what OCTA depicts as a vessel is actually moving blood within the inner, vascular lumen. Further, OCTA will depict all moving particles, thus also suspended scattering particles in motion (SSPiM), regularly seen in exudative maculopathies [27].

OCTA provides-in contrast to dye-based imaging tools-depth resolution images visualizing the deep and superficial vessels as well as the middle capillary plexus and choriocapillaris $[5,6,28]$. Swept source OCTA will be also able to exhibit deeper choroidal vessels. It provides a high segmentation ability (1- to $10-\mu \mathrm{m}$ resolution), which is based on the concept known as inferometry using an optical fiber-based system [3, 28]. Hence, OCTA gives us the possibility to image the different retinal and choroidal vascular layers in multiple en face images, as opposed to single en face view in FA and ICGA.

It is non-invasive and, for ophthalmological use, mainly based on three OCTA techniques: speckle variance, amplitude decorrelation, or phase variance [28]. Speckle variance quantifies the changes in speckle pattern to visualize motion, that is, a higher variance of amplitude changes with flow than in a non-moving sample [28].

Similarly, in amplitude decorrelation, the amplitude of a signal is used for correlation as a metric to detect flow. In case of flow, the decorrelation of the amplitude calculated between the B-scans is higher than in a non-moving sample [28]. 
Contrarily, phase variance does not include amplitude variations, but only changes in phase. The variance is higher in the presence of flow than in static areas [28].

Like any other imaging device, OCTA has limitations in its applicability and validity. One major issue is artifacts.

A false positive flow can be due to eye and head movement, which can lead to artifacts that make the picture "noisy," and should be avoided as much as possible by using eye tracking systems. However, the corrected pictures may have the appearance of a patchwork and show vascular doubling [10]. Furthermore, low flow systems (choroid or vitreous) can cause noise [29]. The artifact of noise can tentatively be prevented by introducing signal threshold levels, yet this counteraction itself may lead to attenuation artifact-induced interpretation errors [29]. Reduction of background noise is manufacturer specific and the procedure is not always transparent for the user, and can lead to signal loss as for the case of smaller vessels, whose already diminished signal might then be further attenuated [29].

False-negative flow due to low decorrelation happens when the blood flow is too slow or too fast [10]. It can also be caused by projection artifacts beneath the perfused vasculature targeted in the investigation, because the reflected light passing through overlying vessels varies over time and changes the reflection of underlying structures [6]. Thus, at the level of RPE or choroid, one would still see retinal vessels [6]. Additionally, in case of media or other pathological opacities, such as aggregations in the vitreous, placoid chorioretinitis, or chorioretinal granulomata, a shadowing artifact can occur [10]. Dry eyes may be a problem, leading to media opacity, but the quality of the image can be improved by optimal lubrification [29]. Another issue may be cataract and anterior segment inflammation, which may lead to false low quantitative measurements despite good image quality [30]. But, of course, these media opacities may also impair the quality of other diagnostic imaging.

Further, due to a fixed interscan time, only blood flow at a certain speed can be captured and blood flux but not the speed of blood flow may be captured with commercially available devices [31]. Another limitation includes the limited comparability among different devices due to different methods used to generate flow motion but also due to different segmentation-approached algorithms and artifact removal algorithms [32, 33].

Finally, as compared to dye-based angiography which can obtain ultra-widefield images, OCTA is limited when it comes to the assessment of peripheral findings with a maximum of $15 \times 9$ or $12 \times 12 \mathrm{~mm}$ in swept-source OCTA (SS-OCTA), as further increasing image size would mean a tradeoff in image quality [34]. To date, widefield images can only be obtained by montaging OCTA images of a smaller field [34]. Montaging software is still in the progress of development.

\section{About the implementation of optical coherence tomography angiography as a diagnostic tool in uveitis}

Vessels of different structures in the eye are involved in or are the origin of different types of uveitis. Until now, the gold standard for diagnosing and managing uveitis has been FA and ICGA, as for assessing disease activity and imaging the retinal or choroidal vasculature. OCT is used to capture ME, and autofluorescence imaging to detect involvement of the RPE and outer retina.

As mentioned above, FA and ICGA have several limitations for their validity, especially when it comes to the quest of understanding the three-dimensionality and the pathohistological correlates.

OCTA has not yet been established, but gets more and more involved as another complementary imaging tool to fill some of the gaps that are left by the conventional angiographies.

\section{About optical coherence tomography angiography in anterior uveitis}

OCTA devices, as an additional algorithm of the OCT, can obtain information about the posterior, but also the anterior segment; yet, studies on the application of OCTA in eyes with anterior uveitis are still quite rare [19, 35-38]. Similar to FA, OCTA is incapable of visualizing the ciliary body, which is also affected in anterior uveitis, but it can visualize iris hyperemia and iris neovascularization, as a possible complication in anterior uveitis, and would, theoretically, allow a quantitative and objective follow-up for patient at risk for neovascularization of the iris [39]. Limitations are set by pupil diameters, iris color diversity, and optical distortion caused by anterior tissue refraction of the OCT beam, especially the cornea $[19,39]$.

In a cross-sectional observational clinical study, anterior segment OCTA was evaluated in 20 normal irides to analyze anterior segment and iris vasculature [40]. In this study, the usability of OCTA was found to be beneficial in ruling out ischemic conditions and in detecting iris and ciliary body tumors, as well as in traumatic and surgical conditions of the anterior segment, since eyes with a history of uveitis were excluded [40].

Compared to FA, iris pigmentation is still a problem in OCTA, because it blocks imaging of the iris vasculature, but OCTA provides better quality images in darker irides and more pigmented areas of the iris compared to FA [40]. 
One study quantified retinal capillary density in uveitic eyes and found decreased parafoveal capillary density not only in intermediate and posterior uveitis, but also in eyes with anterior uveitis irrespective of presence or absence of a ME [36].

\section{About optical coherence tomography angiography in intermediate uveitis}

Intermediate uveitis (IU), defined by an intraocular inflammation mainly apparent in the vitreous and at the peripheral retina, cannot directly be pictured by OCTA, as the main affected structures, the pars plana or the ciliary body, are out of its reach.

In a case-control study (29 eyes with IU versus 30 healthy eyes), reduced vascular density and complexity in superficial as well as deep retinal layers and altered choriocapillaris perfusion were present in patients with IU, meaning that macular microvasculature-regardless if ME was present-was altered [41].

In a prospective cross-sectional study, 156 eyes, including 120 with IU and 36 with concomitant vasculitis, were evaluated using widefield swept-source SS-OCTA [42]. OCTA capillary non-perfusion and reduced perfusion were more frequently observed in the choroid, choriocapillaris, and deep capillary plexus (DCP) than in the superficial capillary plexus (SCP), and no association was observed between peripheral capillary leakage on FA and non-perfusion or reduced peripheral perfusion on widefield OCTA [42].

At the same study site, another prospective, cross-sectional study using SS-OCTA was performed to evaluate vascular changes in patients with intermediate uveitis with or without retinal vasculitis evaluating OCTA scans (widefield montage and central $3 \times 3 \mathrm{~mm}$ slabs) of 93 eyes of 58 patients with IU and 33 healthy age-matched controls [43]. Although wide field images could give important information about peripheral vascular changes, their lower resolution limits the detectability of flow alterations compared to the high resolution of the central scans. Microvascular changes were in most IU cases found at the level of the SCP and DCP, the choriocapillaris and the choroid and change of central vascular density found in the central scans did not correlate to alterations found on wide field OCTA [43]. It was also shown that rather the presence of an epiretinal membrane and a ME than the disease entity had an effect on the FAZ size [43].

In summary, intermediate uveitis, with or without associated vasculitis and in the presence or absence of $\mathrm{ME}$ and ERM, leads to an alteration and decrease of the retinal parafoveal capillary density and to an alteration of the FAZ. Capillary changes may be also found beyond the posterior pole on wide field OCTA.
Interestingly, not only the retinal vasculature seems to be altered but also the choriocapillaris and the choroid, which definitely warrants further evaluation. Data on active eyes are sparse and are needed as well to figure out whether indirect signs of disease activity can be visualized using OCTA.

\section{About optical coherence tomography angiography in posterior uveitis}

The definition of posterior uveitis includes focal, multifocal, or diffuse choroiditis, chorioretinitis, retinochoroiditis, retinitis, and neuroretinitis [44]. They can be infectious or noninfectious, be part of a systemic disease, or limited to the ocular appearance as an ocular syndrome.

These findings are, as mentioned earlier, commonly diagnosed with the help of dye-based angiographies, in addition to funduscopy, and, in some uveitis types, autofluorescence imaging.

Vasculitis, also a common sign of various forms of posterior uveitis, is defined as retinal vascular nonperfusion, retinal hemorrhages, vascular sheathing, overlying vitritis, and leakage on fluorescein angiography [44]. As for affection of the arterial system, vasculitis can be caused by a systemic vasculitis, for example, polyarteritis nodosa, systemic lupus erythematosus, or granulomatosis with polyangiitis, formerly Wegener's granulomatosis, but also by Behçet's disease. If the venular branch of the vascular arcades predominantly shows signs of vasculitis (like sheathing or inflammatory occlusion), the condition is rather associated with sarcoidosis, multiple sclerosis, or tuberculosis, but can also be seen in primary intermediate uveitis or in birdshot [8].

Though there may be various restrictions in OCTA image quality in vasculitis such as vitritis or bleeding, OCTA can be a useful or even superior imaging tool. In some vasculitis cases, neovascularization obscured by retinal hemorrhage, early peripapillary neovascular proliferation, or telangiectasia were better detectable than in FA, as shown in an observational case series of 19 eyes with various uveitis types causing vasculitis [9].

Most of all, OCTA seems to be important in revealing capillary non-perfusion areas in retinal vasculitis. As concluded in a prospective, comparative, cross-sectional study with 44 eyes and a smaller retrospective case series, OCTA unveils microvascular loss of flow in areas affected by vasculitis as diagnosed via FA, which were undetectable with funduscopy, as funduscopic signs of ischemia, such as cotton wool spots or faint retinal whitening, are not present $[7,8]$. In a case of occlusive vasculitis in a West Nile virus infection, OCTA was even estimated to be superior to FA, in detecting ischemic retinal capillary changes [45].

In Behçet's retinal vasculitis, OCTA revealed that the DCP is more affected than the superficial layer, as shown 
in an analytic cross-sectional study including 37 eyes [46]. This was confirmed by a study group, which tested an algorithm for OCTA by mapping the perifoveal region with two concentric circles, using diameters of 1 and $3 \mathrm{~mm}$; furthermore, these circles were divided into superior, inferior, temporal, and nasal regions and categorized into $\mathrm{DCP}$ and $\mathrm{SCP}$, the latter being additionally divided into small and capillary vessels [47]. They revealed that hypoperfusion, mainly in the inferior macular region, is most affected, with the DCP being more affected than the SCP in patients with Behçet's disease [47]. The finding of low capillary vessel density with DCP being more affected was affirmed by a very recent study evaluating 32 eyes of patients compared to 30 healthy eyes [48].

This is of significant importance, as in patients with Behçet's disease, the foveal avascular zone cannot conclusively be assessed by FA because of dye leakage, due to vasculitis. Even in the eyes of patients that are categorized as eyes without ocular involvement by conventional imaging techniques, OCTA can reveal microvascular changes, as shown by a conducted investigation of 20 eyes [49]. Particularly, all eyes showed parafoveal capillary telangiectasia in the DCP, and a majority of cases showed capillary retinal hypoperfusion on OCTA [49]. Thus, OCTA seems to be a more reliable technique for monitoring these patients than FA, which is important in detecting early risk of central loss of vision $[7,9,46]$. However, when scrutinizing possible artifacts, one has to consider the restriction in interpretation regarding false-negative flow: in this case, a too slow flow could also be the reason for a false-negative darkening in the OCTA images, possibly explaining the missing funduscopic signs of ischemia $[7,10]$.

Another sign of posterior uveitis may be granulomata of the retina and choroid, which can be part of a systemic granulomatous disease, such as tuberculosis, sarcoidosis, Lyme disease, or syphilis. Granulomata, considered from a histopathological point of view, usually consist of macrophages and epithelioid cells encircled by lymphocytes forming nodules, caseating, as in the case of tuberculosis, or non-caseating, as, for example, in sarcoidosis. From the clinical point of view, so-called granulomata in the anterior chamber do not necessarily meet these histological criteria. Small granulomata of the retina are not visible in OCTA, but fullthickness granulomata can be visible in the form of hyporeflectivity, corresponding to reduced flow [19].

Looking at sarcoidosis more specifically, besides the OCTA results for granulomata, OCTA findings of the SCP and DCP, as well as the choriocapillaris, seem to be similar to those described in Behçet's disease: a casecontrol, cross-sectional observational study with 19 eyes of 12 patients and 19 healthy control eyes showed a higher sensitivity of OCTA than FA in assessing macular microvascular abnormalities [50], with the DCP appearing more affected by hypo-perfusion/non-perfusion than the SCP, but with the SCP being more affected by the presence of capillary abnormalities. Visual acuity showed a positive correlation with the capillary vessel density at the level of the SCP, which might explain the involvement of the SCP at an advanced stage of the disease [50]. The choriocapillaris also showed flow void areas on OCTA in $42.1 \%$ of the sarcoidosis eyes, likely explained by active granulomata, chronic tissue damage secondary to previously active granulomata (mechanically), or the presence of focal choroidal arteriolitis [50].

Deep choroidal granulomata, such as in Vogt-Koyanagi-Harada disease (VKH), visible on ICGA and EDI-OCT, cannot be assessed by conventional OCTA. However, hypoperfusion in the overlying areas of the choriocapillaris can be detected by OCTA, as shown in a prospective study with ten affected eyes [51]. In turn, combined with ICGA and EDI-OCT, the technique of OCTA was considered to be a convenient imaging tool not only to diagnose, but also to follow-up cases of acute $\mathrm{VKH}$, follow treatment response, and depict recurrences and reduce the use of ICGA [51].

\section{OCTA in secondary complications of uveitis}

One of the most frequent complications in posterior or panuveitis is the development of choroidal neovascularization (CNV), disrupting Bruch's membrane and resulting in central vision loss, if untreated. The underlying disease can be of infectious or noninfectious origin, usually associated with scar formation, lesions, or choroidal granulomata [15]. Based on classification in age-related macula disease, $\mathrm{CNV}$ can be located subretinally (type 1), in the outer retina (type 2 ), or both (mixed type). Inflammatory $\mathrm{CNVs}$ are mostly detected as type $2 \mathrm{CNV}$; however, a minority of patients may also exhibit a type 1 component [15, 52 , 53]. One problem in diagnosing inflammatory $\mathrm{CNV}$ with FA is the possible similar appearance of CNV (early iso- or hyperfluorescence and late hyperfluorescence due to leakage) and inflammatory lesions (early iso- or hypofluorescence and late hyperfluorescence due to leakage in active or staining in inactive lesions) [15]. To differentiate these conditions, ICGA and OCT are commonly used for additional diagnosing and follow-up of inflammatory CNVs. However, as a secondary, inflammatory $\mathrm{CNV}$ does not necessarily present with a sub- or intraretinal fluid on OCT and may just show an increase in subretinal hyperreflectivity on OCT, further assessment tools are warranted. OCTA was identified as a very helpful tool to distinguish inflammatory lesions from CNV [54-56] (Figs. 1 and 2). Moreover, in several case series, OCTA was helpful in detecting $\mathrm{CNV}$, where FA did not provide 


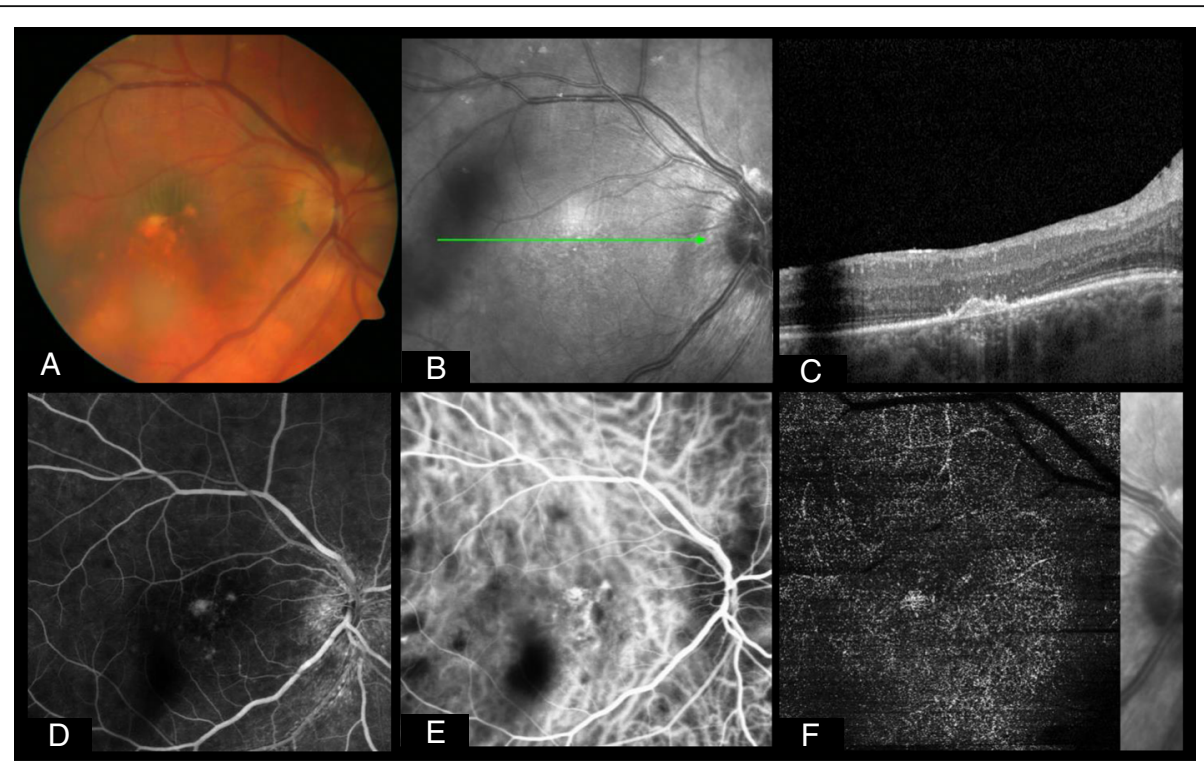

Fig. 1 This patient diagnosed with birdshot retinopathy had been treated with intravitreal steroids abroad due to uveitic macular edema prior to final diagnosis. At first presentation, vision was already decreased to 20/100 on the right eye and 20/200 on the left eye, respectively. On both eyes, there was central atrophy of outer retinal layers besides typical yellow-white lesions on the fundus (a) and furthermore persisting macular edema on the left eye (not shown). These pictures reveal the presence of a choroidal neovascularization (CNV) of the right eye, although there was no intraretinal fluid present on the optical coherence tomography (OCT) scan around a suspicious lesion (b and $\mathbf{c}$ ). Fluorescence angiography peak phase shows light hyperfluorescence of this lesion besides smaller hyperfluorescent spots corresponding to small pigment epithelial detachments (d). On indocyanine green angiography, the birdshot lesions are typically hypocyanescent, but here, central hypercyanscence can be noted (e). OCT angiography confirms a quiescent subretinal (type 1) CNV (f)

any hints, especially when considering type $1 \mathrm{CNV}$ [53, 57]. Significantly more inflammatory CNVs are detected using OCTA than FA; up to $83 \% \mathrm{MCP} / \mathrm{PIC}$ lesions present flow changes consistent with a $\mathrm{CNV}$ [55-57]. A useful collection of the most important references regarding this topic can be found in a review written by Pichi et al. [19].

Another common complication in IU is ME, which, up to now, was a favored focus of previous OCTA studies.

A prospective observational OCTA study including 74 eyes separated into five groups (posterior uveitis with or without ME, anterior uveitis with or without $\mathrm{ME}$, and healthy controls) showed that, when compared to healthy controls, eyes with non-infectious posterior uveitis with or without ME had a significantly larger deep foveolar avascular zone, and eyes with anterior uveitis and ME had a significantly larger deep and superficial foveolar avascular zone [58]. A possible explanation for these findings might be a peripheral displacement of retinal capillaries as a result of the formation of cystoid spaces or cysts, preferentially leading to non-perfusion areas [58].

Uveitic ME was associated with significant changes in the deep retinal layer, regardless of projection artifacts, correlating well with the location of intraretinal cystoid spaces in the inner retina (generally inner nuclear and plexiform layers), as shown by a cross-sectional, observational case series of eyes with anterior, posterior, or panuveitis and healthy controls (but no cases of intermediate uveitis) [36]. This is thought to represent an actual change in the capillary density owing to ME, but a physical displacement of retinal capillaries by the ME remains a plausible interpretation [36]. It was summarized that qualitative and quantitative changes in the parafoveal capillary density and morphology of subjects with uveitis can reliably be detected using OCTA [36].

\section{About optical coherence tomography angiography in white dot syndromes}

There are multiple publications on OCTA in the clinical spectrum of so-called white dot syndromes, a heterogenous group of various forms of posterior or panuveitis having light fundus lesions as at least one common clinical distinguishing sign. The group of diseases that constitute the white dot syndromes include acute posterior multifocal placoid pigment epitheliopathy (APMPPE), serpiginous choroiditis, multiple evanescent white dot syndrome (MEWDS), multifocal choroiditis and panuveitis (MCP), punctate inner choroidopathy (PIC), diffuse subretinal fibrosis (DSF), presumed ocular histoplasmosis syndrome (POHS), and birdshot retinochoroidopathy (BSR). Also, acute macular neuroretinopathy (AMN) and acute zonal 


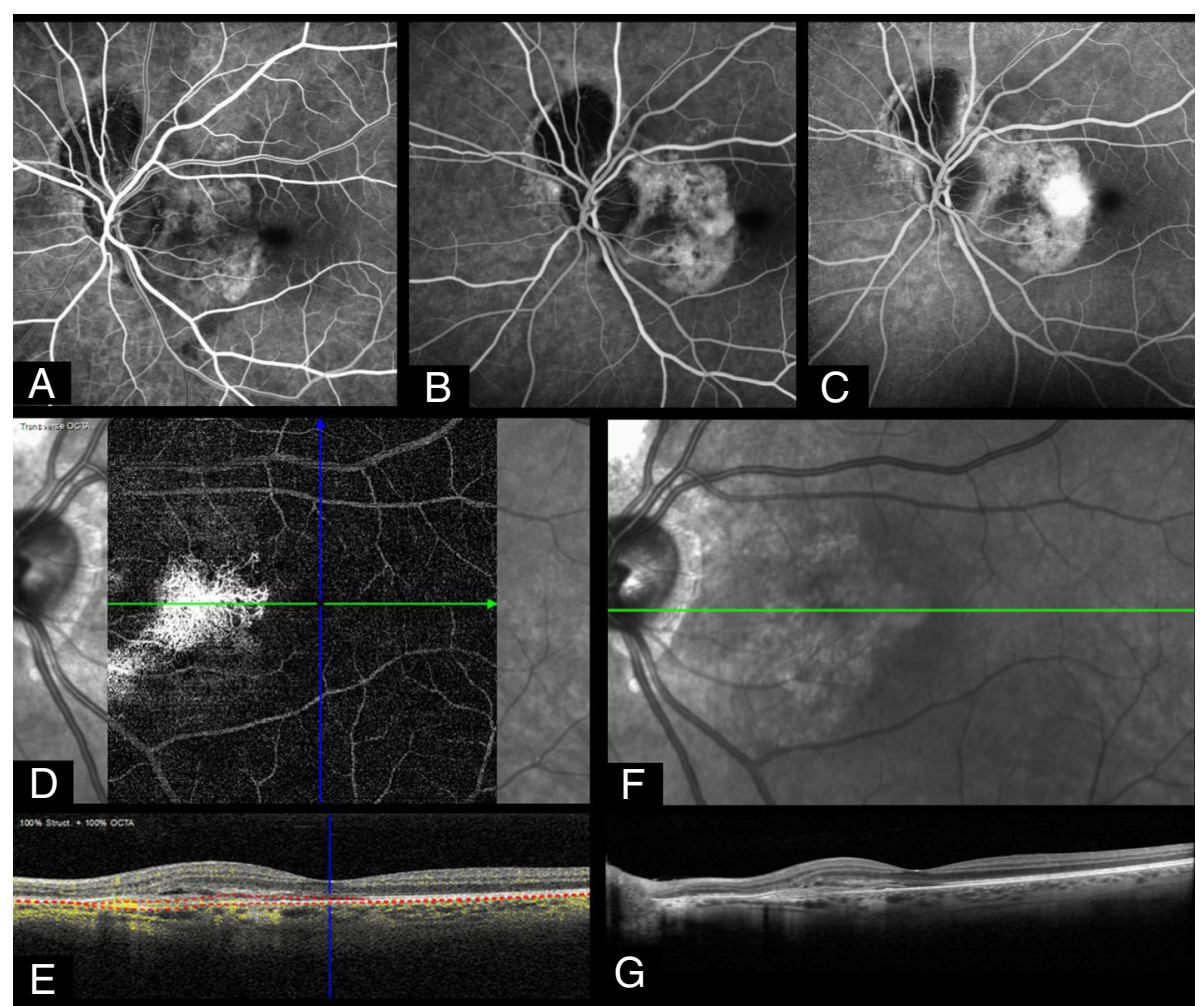

Fig. 2 This 49-year-old lady presented with a 6-week history of reduced vision in the left eye. Visual acuity at presentation was 6/12 in the affected eye, which also showed a chorioretinal scar from a past toxoplasmosis-related chorioretinitis. Fluoresceine angiography revealed a parafoveal spot of active leakage from early- (a) through mid- (b) to late-phase (c). Optical coherence tomography angiography (OCTA) confirmed the presence of a vascular network (d) between the retinal pigment epithelium and Bruch's membrane (e). Structurally, this corresponded to pigment changes on infrared imaging (f) and subretinal fluid next to a fibrovascular pigment epithelial detachment on OCT (g)

occult outer retinopathy (AZOOR) belong to the category of white spot syndromes.

To date, quite a number of reports on OCTA in white dot syndromes have been published (except for DSF), but, given the low incidence of these diseases, most are case series or case reports (see Table 1).

\section{Acute posterior multifocal placoid pigment epitheliopathy (APMPPE)}

APMPPE or multifocal ischemic choroidopathy is a rare type of uveitis, which is characterized by light yellow lesions localized in the outer retina, the retinal pigment epithelium (RPE), and the choroid, due to inflamed choriocapillaris, RPE, and outer layers of the retina. Typical FA findings in the acute phase of the disease are an early blockage of the choroidal background fluorescence under the active lesions, and late staining, whereas in ICGA, these lesions are hypocyanescent during early and late phases of the disease, interpretable as hypoperfusion of the choriocapillaris. In the later course of the disease, late phase FA exhibits mottling hyperfluorescence, staining, and window defects due to scarring of RPE, whereas ICGA patterns remain the same. Early in the course of the disease, OCTA shows normal perfusion patterns of the superficial and deep layers of the retina, but reduced perfusion of the choriocapillaris and choroid like, not unexpectedly, in FA and ICGA, and also as areas of altered FAF [59-61]. Over time, the extent of the non-perfused areas decreases and signs of vascular reperfusion can be noted, but persistent flow void remains at the level of the choriocapillaries [62, 63]. A multimodal imaging example comparing early and late stage of the disease is given in Fig. 3. Disease-specific limitations of the method are its limited ability to give flow information of the peripheral retina and the limited resolution of the choroidal vasculature, due to the overlying thickened RPE and further inflammatory changes.

\section{Serpiginous choroiditis}

Serpiginous choroiditis is a rare ocular pathology that presents with binocular, but asymmetric grayish or yellow inflammatory lesions, which develop in an irregular serpentine pattern. These lesions develop into an atrophy of the outer retina, RPE, and the choriocapillaris. 
Table 1 Summary of publications on the implementation of OCTA in white dot syndromes

\begin{tabular}{llll}
\hline Disease & Publication & $\begin{array}{l}\text { Number of eyes/ } \\
\text { patients }\end{array}$ & Study type \\
\hline MCP and PIC & $\begin{array}{l}\text { Zahid S, Chen Kc, Jung } \\
\text { Jj, Balaratnasingam C, } \\
\text { Ghadiali Q, Sorenson J, }\end{array}$ & $\begin{array}{l}18 \text { eyes of 14 } \\
\text { patients with MCP }\end{array}$ & $\begin{array}{l}\text { Descriptive, } \\
\text { retrospective study }\end{array}$ \\
& Et Al. Optical coherence & & \\
& tomography & \\
& angiography Of & \\
& chorioretinal lesions due & \\
& to idiopathic multifocal & \\
& choroiditis. Retina. & \\
& 2017;37(8):1451-63. &
\end{tabular}

Levison Al, Baynes Km, Lowder Cy, Kaiser Pk Srivastava Sk. Choroidal neovascularisation on optical coherence tomography angiography in punctate inner choroidopathy and multifocal choroiditis. $\mathrm{Br}$ J Ophthalmol.

2017;101(5):616-22.

Cheng L, Chen X, Weng S, Mao L, Gong Y, Yu S, Et Al. Spectral-domain optical coherence tomography angiography findings in multifocal choroiditis with active lesions. Am J Ophthalmol. 2016;169:145-61.
Cerquaglia A, Lupidi M, Fiore T, laccheri B, Perri $P$, Cagini C. Deep inside multifocal choroiditis: an optical coherence tomography angiography approach. International Ophthalmology.
17 eyes of 12 patients, (7 with PIC descriptive case and 5 with MCP), series out of which 9 patients longitudinally followed and 11 identified with CNV

\section{2 eyes of $26 \mathrm{MCP}$} patients (14 bilaterally affected and 12 unilaterally affected)

Reliability and validity analysis (prospective)

of discussion
OCTA flow signals
consistent with

neovascularization were identifiable in $83 \%$ of eyes including $0 \%$ of subretinal pigment epithelium, $91 \%$ of subretinal, and $100 \%$ of mixed lesions

OCTA also identified CNV in cases where FA was inconclusive for the presence of CNV

No change in quantitative measurements of greatest linear diameter, area, and largest vessel diameter of the neovascular complex following anti-VEGF therapy was observed

OCTA identified CNV in cases where FA was inconclusive for the presence of CNV Correlation between OCT and OCTA findings as for suspected activity could confirm the diagnosis

OCTA could be particularly helpful in distinguishing CNV from inflammatory lesions

20 of 23 active CNV cases were confirmed on OCTA

3 invalid OCTA results due to motion artifacts 32 of 34 inflammatory lesions in 13 eyes did not show blood flow in the outer retina on OCTA while the other 2 did

OCTA could be helpful in distinguishing CNV from inflammatory lesions

OCTA could not reliably give information about CNV activity (in contrast to FA) and thus, FA was still necessary to make therapy decisions in recurrent cases

\section{1 eye of 1 patient $\quad$ Single case report}

Distinction of inflammation versus CNV is possible by multimodal imaging, especially OCTA was crucial for the therapeutic decision in this particular case OCTA may help in
OCTA device

Optovue Avanti-RTVue-XR

(Optovue, Fremont, California, USA)

or

Cirrus Angioplex OMAGC (Carl

Zeiss Meditec Inc)

Optovue Avanti-RTVue-XR (Optovue, Fremont, California, USA)

Optovue RTVue XR Avanti

(Optovue, Inc., Fremont, (alifornia, USA)

OCTA prototype based on Spectralis OCT2 (Heidelberg Engineering, Heidelberg, Germany) 
Table 1 Summary of publications on the implementation of OCTA in white dot syndromes (Continued)

\begin{tabular}{|c|c|c|c|}
\hline Disease & Publication & $\begin{array}{l}\text { Number of eyes/ } \\
\text { patients }\end{array}$ & Study type \\
\hline \multicolumn{4}{|c|}{ 2017;37(4):1047-51. } \\
\hline & $\begin{array}{l}\text { Nakao S, Kaizu Y, } \\
\text { Oshima Y, Sakamoto T, } \\
\text { Ishibashi T, Sonoda Kh. } \\
\text { Optical coherence } \\
\text { tomography } \\
\text { angiography for } \\
\text { detecting choroidal } \\
\text { neovascularization } \\
\text { secondary to punctate } \\
\text { inner choroidopathy. } \\
\text { Ophthalmic Surg Lasers } \\
\text { Imaging Retina. } \\
\text { 2016;47(12):1157-61. }\end{array}$ & 2 eyes of 1 patient & Single case report \\
\hline
\end{tabular}

Astroz, P., Et Al., Optical coherence tomography angiography to distinguish choroidal neovascularization from macular inflammatory lesions in multifocal choroiditis. Retina, 2018. 38(2): P. 299-309.
18 eyes of 13 patients

Retrospective case series
Yannuzzi $\mathrm{Na}$,

Swaminathan Ss, Zheng

F, Miller A, Gregori G,

Davis Jl, Et Al. Swept-

Source OCT angiography shows sparing of the choriocapillaris in multiple evanescent white dot syndrome. Ophthalmic Surg Lasers Imaging Retina. 2017:48(1):69-74.

Pichi F, Srvivastava Sk, 29 eyes of 35 Chexal S, Lembo A, Lima Lh, Neri P, Et Al. En face patients

of discussion

\section{characterizing}

inflammatory lesions pattern and to detect the presence of CNV within a subretinal inflammatory or fibrotic tissue

OCTA detected abnormal flow in the outer retina, corresponding to type 2 CNV in PIC lesions

OCTA showed remodeling of the choroidal capillaries and decreased flow in CNV after the treatment with anti-VEGF

OCTA could be useful for the follow-up and evaluation of therapeutic strategies used to treat $\mathrm{PIC}$ and might prevent excessive administration of anti-VEGF therapy

Active CNV and inactive CNV were not significantly different concerning the different features on OCTA 5/15 (33.3\%) eyes presented multifocal high-flow networks in the outer retina segmentation on OCTA images

After anti-VEGF treatment, CNV size decreased on OCTA (but not statistically significant)

OCTA can be useful in differentiating active inflammatory chorioretinal lesions from CNV, but not distinguish between active and inactive CNV

OCTA revealed choriocapillary circulation to be normal in the acute phase Suggestion that MEWDS is a result of an injury of the photoreceptors, and that hypofluorescence in ICGA imaging may be caused by irregular staining of tissue by extravasated ICG dye rather than a choroidal vascular abnormality

Retrospective case series
Spectral-domain OCT (SD-OCT)

(HRA; Heidelberg Engineering, Heidelberg, Germany)
Optovue RTVue XR Avanti (Optovue, Inc., Fremont, California, USA)
Swept-source OCTA, no details available
Normal OCTA findings of the choroid and choroidal
Optovue Avanti-RTVue-XR (Optovue, Fremont, California, USA) 
Table 1 Summary of publications on the implementation of OCTA in white dot syndromes (Continued)

\begin{tabular}{|c|c|c|c|c|c|}
\hline Disease & Publication & $\begin{array}{l}\text { Number of eyes/ } \\
\text { patients }\end{array}$ & Study type & $\begin{array}{l}\text { Main results and points } \\
\text { of discussion }\end{array}$ & OCTA device \\
\hline & $\begin{array}{l}\text { optical coherence } \\
\text { tomography and optical } \\
\text { coherence tomography } \\
\text { angiography of multiple } \\
\text { evanescent white dot } \\
\text { syndrome: new insights } \\
\text { into pathogenesis. } \\
\text { Retina. 2016;36 Suppl } \\
\text { 1:S178-S88. }\end{array}$ & & & $\begin{array}{l}\text { hypofluorescence in } \\
\text { ICGA could be due to } \\
\text { the reduced absorption } \\
\text { capacity of } \\
\text { malfunctioning RPE } \\
\text { (theory of Chang et al.) } \\
\text { Proposition that MEWDS } \\
\text { is primarily the result of } \\
\text { inflammation at the RPE } \\
\text { and outer } \\
\text { photoreceptor level } \\
\text { leading to a } \\
\text { "photoreceptoritis" } \\
\text { Temporary loss of the } \\
\text { inner and outer } \\
\text { segments could be due } \\
\text { to inflammation of the } \\
\text { photoreceptor segments } \\
\text { or the RPE with } \\
\text { secondary } \\
\text { photoreceptor } \\
\text { involvement } \\
\text { Hyperautofluorescent } \\
\text { "spots" on FAF may be } \\
\text { the result of either an } \\
\text { unmasking effect of RPE } \\
\text { autofluorescence or } \\
\text { secondary to thickened } \\
\text { RPE cells } \\
\text { Hyperautofluorescent } \\
\text { "dots" may represent } \\
\text { disrupted and shed } \\
\text { photoreceptor segments } \\
\text { that stain with FA and/ } \\
\text { or associated Muller cell } \\
\text { disruption }\end{array}$ & \\
\hline & $\begin{array}{l}\text { Pereira F, Lima Lh, De } \\
\text { Azevedo Agb, Zett C, } \\
\text { Farah Me, Belfort R, Jr. } \\
\text { Swept-source OCT in pa- } \\
\text { tients with multiple } \\
\text { evanescent white dot } \\
\text { syndrome. J Ophthalmic } \\
\text { Inflamm Infect. } \\
\text { 2018:8(1):16. }\end{array}$ & 2 eyes of 2 patients & Case reports & $\begin{array}{l}\text { Normal OCTA findings } \\
\text { of outer retina and of } \\
\text { choriocapillaris during } \\
\text { the acute phase of } \\
\text { disease may suggest the } \\
\text { primary injury in the } \\
\text { outer retina and the } \\
\text { photoreceptors }\end{array}$ & $\begin{array}{l}\text { Spectral-domain-OCTA (DRI } \\
\text { Swept } \\
\text { Source OCT Triton, Topcon, } \\
\text { Japan) }\end{array}$ \\
\hline & $\begin{array}{l}\text { Nozaki M, Hamada S, } \\
\text { Kimura M, Yoshida M, } \\
\text { Ogura Y. Value of OCT } \\
\text { angiography in the } \\
\text { diagnosis of choroidal } \\
\text { neovascularization } \\
\text { complicating multiple } \\
\text { evanescence white dot } \\
\text { syndrome. Ophthalmic } \\
\text { Surg Lasers Imaging } \\
\text { Retina. 2016;47(6):580-4. }\end{array}$ & 1 eye of 1 patient & Case report & $\begin{array}{l}\text { OCTA can be a useful } \\
\text { tool and easier } \\
\text { applicable than ICGA for } \\
\text { diagnosing and follow- } \\
\text { up of type } 2 \text { CNV in } \\
\text { MEWDS, also in case of } \\
\text { recurrence }\end{array}$ & $\begin{array}{l}\text { Optovue Avanti-RTVue-XR } \\
\text { (Optovue, Fremont, California, } \\
\text { USA) }\end{array}$ \\
\hline POHS & $\begin{array}{l}\text { Liu Tya, Zhang Ay, } \\
\text { Wenick A. Evolution of } \\
\text { choroidal } \\
\text { neovascularization due } \\
\text { to presumed ocular } \\
\text { histoplasmosis } \\
\text { syndrome on } \\
\text { multimodal imaging } \\
\text { including optical } \\
\text { coherence tomography }\end{array}$ & 2 eyes of 1 patient & Single case report & $\begin{array}{l}\text { OCTA made CNV lesions } \\
\text { visible when no CNV } \\
\text { activity was seen on FA } \\
\text { or SD-OCT at follow-up } \\
\text { visits } \\
\text { Suggestion that OCTA is } \\
\text { more sensitive than FA } \\
\text { or SD-OCT in detecting } \\
\text { the presence of persist- } \\
\text { ent CNV related to }\end{array}$ & $\begin{array}{l}\text { Spectral-domain-OCTA, no } \\
\text { details available }\end{array}$ \\
\hline
\end{tabular}


Table 1 Summary of publications on the implementation of OCTA in white dot syndromes (Continued)

\begin{tabular}{|c|c|c|c|c|c|}
\hline Disease & Publication & $\begin{array}{l}\text { Number of eyes/ } \\
\text { patients }\end{array}$ & Study type & $\begin{array}{l}\text { Main results and points } \\
\text { of discussion }\end{array}$ & OCTA device \\
\hline & $\begin{array}{l}\text { angiography. Case } \\
\text { Reports In } \\
\text { Ophthalmological } \\
\text { Medicine. } \\
\text { 2018;2018:4098419. }\end{array}$ & & & $\begin{array}{l}\text { POHS } \\
\text { The central trunk of CNV } \\
\text { can be relatively } \\
\text { resistant to anti-VEGF } \\
\text { treatments } \\
\text { Increase in CNV activity } \\
\text { on OCTA does not } \\
\text { necessarily lead to } \\
\text { significant visual } \\
\text { impairment }\end{array}$ & \\
\hline APMPPE & $\begin{array}{l}\text { Werner Ju, Enders C, } \\
\text { Lang Gk, Lang Ge. Multi- } \\
\text { modal imaging includ- } \\
\text { ing optical coherence } \\
\text { tomography angiog- } \\
\text { raphy in patients with } \\
\text { posterior multifocal plac- } \\
\text { oid pigment epithelio- } \\
\text { pathy. Ophthalmic Surg } \\
\text { Lasers Imaging Retina. } \\
\text { 2017:48(9):727-33. }\end{array}$ & 8 eyes of 4 patients & Case series & $\begin{array}{l}\text { OCTA showed perfusion } \\
\text { defects in } \\
\text { choriocapillaris and } \\
\text { choroid in APMPPE } \\
\text { lesions } \\
\text { OCTA perfusion deficits } \\
\text { resolved in the choroid } \\
\text { and later in the } \\
\text { choriocapillaris over the } \\
\text { course of the disease } \\
\text { Suggestion that } \\
\text { involvement of the } \\
\text { choroidal circulation } \\
\text { leads secondarily to } \\
\text { damage of the outer } \\
\text { retina } \\
\text { OCTA might be able to } \\
\text { replace FA and ICGA for } \\
\text { diagnosing APMPPE }\end{array}$ & $\begin{array}{l}\text { Cirrus } 5000 \text { equipped with the } \\
\text { AngioPlex module (Carl Zeiss } \\
\text { Meditec, Dublin, CA) }\end{array}$ \\
\hline
\end{tabular}

Salvatore S, Steeples Lr, 2 eyes of 1 patient Single case report Ross Ah, Bailey C, Lee

Rw, Carreno E.

Multimodal imaging in

acute posterior

multifocal placoid

pigment epitheliopathy

demonstrating

obstruction of the

choriocapillaris.

Ophthalmic Surg Lasers

Imaging Retina.

2016;47(7):677-81.

Maier M, Wehrmann K,

Lohmann Cp, Feucht N.

[OCT angiography

findings in acute

posterior multifocal

placoid pigment

epitheliopathy

(Apmppe)].

Ophthalmologe.

2017;114(1):60-5.

Heifermann Mj, Rahmani S, Jampol Lm, Nesper PI, Skondra D, Kim La, Et Al.

Acute posterior

multifocal placoid

pigment epitheliopathy

on optical coherence

tomography

angiography. Retina.

2017;37(11):2084-94.

2 eyes of 1 patient Single case report
10 eyes of 5 patients
Retrospective observational case series

OCTA showed isolated choriocapillaris nonperfusion within APMPPE lesions in the active disease phase and improvement in flow over the course of the disease

Choriocapillaris is suggested to be the primary focus of the disease

Hypofluorescent areas visible on ICGA in the early and late phases showed corresponding hypoperfused areas by OCTA of APMPPE lesions

Optovue Avanti-RTVue-XR (Optovue, Fremont, California, USA)

Spectral-domain-OCTA, no details available
In APMPPE lesions, conclusive resolvement of the choroidal vasculature on OCTA was difficult through overlying RPE thickening and inflammatory

changes

In 1 of 5 patients, choriocapillaris flow deficit extended outside the visible intraretinal lesion Recovery of
Optovue Avanti-RTVue-XR (Optovue, Fremont, California, USA) with split-spectrum amplitude-decorrelation angiography software 
Table 1 Summary of publications on the implementation of OCTA in white dot syndromes (Continued)

\begin{tabular}{|c|c|c|c|c|c|}
\hline Disease & Publication & $\begin{array}{l}\text { Number of eyes/ } \\
\text { patients }\end{array}$ & Study type & $\begin{array}{l}\text { Main results and points } \\
\text { of discussion }\end{array}$ & OCTA device \\
\hline & & & & $\begin{array}{l}\text { choroidal flow parallel } \\
\text { with healing of the } \\
\text { APMPPE lesions } \\
\text { Attenuated OCTA signal } \\
\text { related to acute lesions } \\
\text { was impossible to } \\
\text { distinguish from primary } \\
\text { choriocapillaris } \\
\text { nonperfusion on OCTA } \\
\text { Hypointensity on en } \\
\text { face OCT could be due } \\
\text { to projection artifacts } \\
\text { and signal attenuation } \\
\text { from chronic RPE } \\
\text { thickening and } \\
\text { pigmentary of acute and } \\
\text { subacute lesions } \\
\text { Suggestion of theory } \\
\text { that isolated disruption } \\
\text { to the choriocapillaris } \\
\text { leaves the choroid in a } \\
\text { sufficiently functional } \\
\text { state to largely maintain } \\
\text { the RPE/photoreceptor } \\
\text { integrity } \\
\text { Findings support } \\
\text { decreased blood flow to } \\
\text { be consistent with } \\
\text { choriocapillary changes } \\
\text { leading to a primary } \\
\text { ischemic insult to the } \\
\text { RPE rather than a } \\
\text { primary RPE } \\
\text { inflammatory etiology, } \\
\text { but choriocapillaris } \\
\text { changes could also be } \\
\text { secondary to subclinical } \\
\text { overlying RPE and retinal } \\
\text { damage } \\
\text { True course of RPE, } \\
\text { retinal, and choroidal } \\
\text { injury in APMPPE } \\
\text { remains unclear }\end{array}$ & \\
\hline & $\begin{array}{l}\text { Dolz-Marco R, Sarraf D, } \\
\text { Giovinazzo V, Freund Kb. } \\
\text { Optical coherence } \\
\text { tomography } \\
\text { angiography shows } \\
\text { inner clumbrohoroidal } \\
\text { ischemia in acute } \\
\text { posterior multifocal } \\
\text { placoid pigment } \\
\text { epitheliopathy. Retin } \\
\text { Cases Brief Rep. 2017;11 } \\
\text { Suppl 1:S136-S43. }\end{array}$ & 1 eye of 1 patient & Single case report & $\begin{array}{l}\text { OCTA demonstrated } \\
\text { inner choroidal flow } \\
\text { improvement to } \\
\text { accelerate after the } \\
\text { initiation of oral } \\
\text { prednisone } \\
\text { Theory of primary } \\
\text { choroidal } \\
\text { pathophysiology is } \\
\text { supported with OCTA } \\
\text { findings } \\
\text { Hypothesis, that a } \\
\text { compensatory vascular } \\
\text { mechanism is induced } \\
\text { by the more central area } \\
\text { of choroidal ischemia, } \\
\text { because in the acute } \\
\text { phase perilesional areas } \\
\text { show increased inner } \\
\text { choroidal flow that fades } \\
\text { over time } \\
\text { OCTA, compared to } \\
\text { fundus examination, was } \\
\text { more sensitive in }\end{array}$ & $\begin{array}{l}\text { Optovue Avanti-RTVue-XR } \\
\text { (Optovue, Fremont, California, } \\
\text { USA) }\end{array}$ \\
\hline
\end{tabular}


Table 1 Summary of publications on the implementation of OCTA in white dot syndromes (Continued)

\begin{tabular}{lll}
\hline Disease $\quad \begin{array}{ll}\text { Publication } \\
\text { patients }\end{array}$ & $\begin{array}{l}\text { Main results and points } \\
\text { of discussion }\end{array}$ \\
\hline & OCTA device \\
& $\begin{array}{l}\text { detecting new lesions } \\
\text { Compared to ultra- } \\
\text { widefield dye-based an- }\end{array}$ \\
& giographies, en face re- \\
& constructions of OCTA \\
& might be more sensitive, \\
& but conclusive findings \\
outside the posterior & pole are limited
\end{tabular}

De Carlo Te, Bonini Filho Ma, Adhi M, Duker Js. Retinal and choroidal vasculature in birdshot chorioretinopathy analyzed using spectral domain optical coherence tomography angiography. Retina. 2015;35(11):2392-9.
Phasukkijwatana N, lafe N, Sarraf D. Optical coherence tomography angiography of A29

birdshot

chorioretinopathy complicated by retinal neovascularization. Retin Cases Brief Rep. 2017;11 Suppl 1:S68-S72.
Prospective observational review

8 eyes of 4 patients

On OCTA, BSR lesions

showed areas of choriocapillaris flow reduction below retinal pigment epithelium disruption with larger choroidal vessels bordering or traversing those areas

Suggestion of interpretation of those vessels being either a compensatory response by the choroid or being vessels from Sattler's layer that are pushed into the choriocapillaris plane

Flow reduction can be interpreted as greatly reduced blood flow or true choriocapillaris loss OCTA provided limited view of deeper choroidal layers OCTA showed abnormally tortuous vessels and increased intercapillary space in the retinal vasculature in all affected eyes $88 \%$ of affected eyes showed capillary loops and focal dilatations

\section{2 eyes of 1 patient Single case report}

OCTA allowed quantification and specific distinction between superficial and deep capillary plexus pathology in BSR Diffuse reduction in the flow of both the SCP and DCP of the patient as compared with normal eyes, on OCTA OCTA demonstrated the DCP being more affected then the SCP Significant projection artifacts in the OCTA of the DCP were dealt with by adjusting and subtracting procedures DCP was considered to be more prone to hypoxic injury because if its blood supply
AngioVue OCTA software on the com- mercially available Optovue Avanti-RTVue-XR (Optovue, Fremont, California, USA)
Optovue Avanti-RTVue-XR (Optovue, Fremont, California, USA) 
Table 1 Summary of publications on the implementation of OCTA in white dot syndromes (Continued)

\begin{tabular}{|c|c|c|c|c|c|}
\hline Disease & Publication & $\begin{array}{l}\text { Number of eyes/ } \\
\text { patients }\end{array}$ & Study type & $\begin{array}{l}\text { Main results and points } \\
\text { of discussion }\end{array}$ & OCTA device \\
\hline & $\begin{array}{l}\text { Pepple Kl, Chu Z, } \\
\text { Weinstein J, Munk Mr., } \\
\text { Van Gelder Rn, Wang Rk. } \\
\text { Use of en face swept- } \\
\text { source optical coher- } \\
\text { ence tomography angi- } \\
\text { ography in identifying } \\
\text { choroidal flow voids in } 3 \\
\text { patients with birdshot } \\
\text { chorioretinopathy. Jama } \\
\text { Ophthalmology. } \\
\text { 2018;136(11):1288-92. }\end{array}$ & 6 eyes of 3 patients & $\begin{array}{l}\text { Prospective, } \\
\text { longitudinal, } \\
\text { observational case } \\
\text { series }\end{array}$ & $\begin{array}{l}\text { Choroidal flow voids in } \\
\text { SS-OCTA ultra-widefield } \\
\text { images colocalize with } \\
\text { hypofluorescent ICGA le- } \\
\text { sions in BSR } \\
\text { Suggestion that acute } \\
\text { lesions are localized in } \\
\text { Haller's layer and } \\
\text { chronic lesions may } \\
\text { involve the entire } \\
\text { choroid } \\
\text { Hypothesis: true } \\
\text { perfusion abnormality } \\
\text { might be caused by } \\
\text { choroidal vascular } \\
\text { destruction in chronic } \\
\text { disease, as opposite to } \\
\text { flow voids in acute } \\
\text { disease that might be } \\
\text { due to change in the } \\
\text { tissue's optical } \\
\text { properties by the } \\
\text { presence of } \\
\text { inflammatory cells }\end{array}$ & $\begin{array}{l}\text { PLEX Elite } 9000 \text { (Carl Zeiss AG, } \\
\text { Dublin, CA) (widefield images } \\
\text { approximately } 100^{\circ} \text { ) were } \\
\text { achieved by montaging } \\
\text { sixteen } 6 \times 6 \text {-mm or five } 12 \times \\
12-\mathrm{mm} \text { cubes) }\end{array}$ \\
\hline \multirow[t]{3}{*}{$\begin{array}{l}\text { Serpiginous } \\
\text { chorioiditis }\end{array}$} & $\begin{array}{l}\text { El Ameen A, Herbort Cp, } \\
\text { Jr. Serpiginous } \\
\text { choroiditis imaged by } \\
\text { optical coherence } \\
\text { tomography } \\
\text { angiography. Retin } \\
\text { Cases Brief Rep. } \\
\text { 2016;12(4):279-85. }\end{array}$ & 2 eyes of 1 patient & Single case report & $\begin{array}{l}\text { OCTA showed } \\
\text { geographically shaped } \\
\text { dark areas in lesions } \\
\text { suggestive of decreased } \\
\text { flow of the } \\
\text { choriocapillaris } \\
\text { OCTA could replace } \\
\text { ICGA during some of } \\
\text { the subsequent follow- } \\
\text { up visits, whereas at ini- } \\
\text { tial evaluation, ICGA re- } \\
\text { mains preferable } \\
\text { Intermediate phase ICGA } \\
\text { seemed to be more } \\
\text { sensitive than OCTA for } \\
\text { detecting hypoperfusion } \\
\text { Hypoperfused areas } \\
\text { diminished after } \\
\text { cyclosporine was } \\
\text { introduced }\end{array}$ & $\begin{array}{l}\text { Optovue Avanti-RTVue-XR } \\
\text { (Optovue, Fremont, California, } \\
\text { USA) }\end{array}$ \\
\hline & $\begin{array}{l}\text { Montorio D, Giuffre C, } \\
\text { Miserocchi E, Modorati } \\
\text { G, Sacconi R, Mercuri S, } \\
\text { Et Al. Swept-source op- } \\
\text { tical coherence tomog- } \\
\text { raphy angiography in } \\
\text { serpiginous choroiditis. } \\
\text { Br J Ophthalmol. } \\
\text { 2017;102(7):991-95. }\end{array}$ & $\begin{array}{l}22 \text { eyes of } 11 \\
\text { patients }\end{array}$ & $\begin{array}{l}\text { Retrospective cross- } \\
\text { sectional and obser- } \\
\text { vational study }\end{array}$ & $\begin{array}{l}\text { OCTA showed atrophy } \\
\text { of choriocapillaris with } \\
\text { an impairment of its } \\
\text { detectable flow and } \\
\text { greater visibility of } \\
\text { choroidal vessels in } \\
\text { inactive lesions } \\
\text { OCTA showed no } \\
\text { decorrelation signal in } \\
\text { active lesions in } \\
\text { choriocalipparis and the } \\
\text { whole choroid } \\
\text { Vessel density of the } \\
\text { outer border of inactive } \\
\text { lesions seemed to be } \\
\text { lower than vessel } \\
\text { density of unaffected } \\
\text { areas }\end{array}$ & $\begin{array}{l}\text { Swept-source OCTA } \\
\text { (AngioPlex Elite } 9000 \text { SS-OCT, } \\
\text { Carl Zeiss Meditech) }\end{array}$ \\
\hline & $\begin{array}{l}\text { Pakzad-Vaezi K, Khaksari } \\
\text { K, Chu Z, Van Gelder Rn, } \\
\text { Wang Rk, Pepple Kl. }\end{array}$ & $\begin{array}{l}6 \text { eyes of } 3 \text { patients } \\
\text { ( } 4 \text { eyes with } \\
\text { choroidal lesions) }\end{array}$ & $\begin{array}{l}\text { Prospective, } \\
\text { observational case } \\
\text { series }\end{array}$ & $\begin{array}{l}\text { OCTA showed larger } \\
\text { lesions of the } \\
\text { choriocapillaris slab }\end{array}$ & $\begin{array}{l}\text { Swept-source OCTA } \\
\text { PLEX Elite } 9000 \text { (Carl Zeiss AG, } \\
\text { Dublin, CA) }\end{array}$ \\
\hline
\end{tabular}


Table 1 Summary of publications on the implementation of OCTA in white dot syndromes (Continued)

\begin{tabular}{ll}
\hline Disease & \multicolumn{1}{c}{$\begin{array}{l}\text { Number of eyes/ Study type } \\
\text { patients }\end{array}$} \\
\hline angiography of serpigin- \\
ous choroiditis. Ophthal- \\
mology Retina. \\
2018;2(7):712-9. \\
\\
\\
\\
\\
Ahn Sj, Park Sh, Lee Br. 2 eyes of 1 patient $\quad$ Single case report \\
Multimodal imaging \\
including optical \\
coherence tomography \\
angiography in \\
serpiginous choroiditis. \\
Ocul Immunol Inflamm. \\
2017;25(2):287-91. \\
\\
\\
\end{tabular}

Khan Ha, Shahzad Ma. Multimodal imaging of serpiginous choroiditis. Optometry And Vision Science: Official

Publication Of The

American Academy Of

Optometry

2017:94(2):265-9.
Aggarwal, K., A. Agarwal, D. Katoch, M. Sharma And V. Gupta (2017).

"Optical coherence tomography angiography features of
Main results and points

OCTA device

of discussion

than in the outer

nuclear layer slab and

FAF areas

Resolution of those lesions occurred, where OCTA findings were not associated with

corresponding abnormal

FAF (without clinical

scarring after treatment)

OCTA results seem to

support the theory that

the choriocapillaris is the primary site of

pathology

Suggestion of a simple grading system based on OCT, OCA and/or ICGA

OCTA demonstrated

Swept-source OCTA, no details decreased vascularity on the choriocapillaris slab Loss of capillaries is partially replaced with irregular capillaris, but photoreceptor defect persisted following systemic corticosteroid therapy

Choriocapillaris was seen as the main pathology of serpiginous choroiditis which may lead to the photoreceptor disruption

2 eyes of 1 patient Single case report ( 1 eye with choroidal lesions)

OCTA revealed normal retinal architecture in lesions, but disruption of homogeneity of the choriocapillaris

Role of choriocapillaris loss and hypoperfusion as a contributing factor towards the

development of choroidal

neovascularization in the later course is supported by OCTA findings

Choriocapillaris was suggested to be affected most in earlier and later stages of the disease and its involvement might be the possible mechanism behind the development of CNVV in these cases

OCTA en face images showed disruption of both the SCP and DCP with flow deficit in the affected foveal region OCTA showed an
Swept-source OCTA, no details available
2 eyes of 1 patient
(1 eye with macular lesion)
Single case report 
Table 1 Summary of publications on the implementation of OCTA in white dot syndromes (Continued)

\begin{tabular}{|c|c|c|c|c|c|}
\hline Disease & Publication & $\begin{array}{l}\text { Number of eyes/ } \\
\text { patients }\end{array}$ & Study type & $\begin{array}{l}\text { Main results and points } \\
\text { of discussion }\end{array}$ & OCTA device \\
\hline & $\begin{array}{l}\text { acute macular } \\
\text { neuroretinopathy in } \\
\text { dengue fever." Indian J } \\
\text { Ophthalmol } \\
65(11): 1235-1238 .\end{array}$ & & & $\begin{array}{l}\text { increase of size of the } \\
\text { FAZ } \\
\text { SCP and DCP ischemia } \\
\text { on OCTA did not } \\
\text { change much at 6- } \\
\text { month follow-up } \\
\text { OCTA provided insights } \\
\text { into the level of } \\
\text { pathophysiological } \\
\text { alterations in the } \\
\text { affected eyes and } \\
\text { helped in determining } \\
\text { the visual prognosis }\end{array}$ & \\
\hline
\end{tabular}

Casalino, G., A. Arrigo, F. 11 eyes of $7 \quad$ Prospective,

Romano, M. R. Munk, F. patients

Bandello And M. B.

Parodi (2019). "Acute

macular

neuroretinopathy:

pathogenetic insights

from optical coherence

tomography

angiography." $\mathrm{Br}$ J

Ophthalmol 103(3):410-

414

Kulikov, A. N., D. S.

Maltsev And T. A.

Leongardt (2018). Retinal

microvasculature

alteration in paracentral

acute middle

maculopathy and acute

macular

neuroretinopathy: a

quantitative optical

coherence tomography

angiography study. Retin

Cases Brief Rep. https://

doi.org/10.1097/ICB.

0000000000000709

Lee, S. Y., J. L. Cheng, K. M. Gehrs, J. C. Folk, E. H.

Sohn, S. R. Russell, Z.

Guo, M. D. Abramoff

And I. C. Han (2017).

Choroidal features of

acute macular

neuroretinopathy via

optical coherence

tomography

angiography and

correlation with serial

multimodal imaging.

Jama Ophthalmol

135(11): 1177-1183. observational, cross-

sectional study

6 eyes with PAMM Case series and 2 eyes with

AMN of 6 patients
9 eyes of 7 patients Retrospective case series
OCTA revealed that global vascular perfusion is not impaired in the

SCP and DCP, while a general flow void was found to be present in the choriocapillaris and focal impairment of the DCP

Persistent difficulty to determine at which level the primary vascular insult occurs

OCTA revealed

decreased vessel density of the SCP and DCP and changes in the shape of the superficial FAZ in PAMM and AMN eyes No difference was found in the FAZ area between PAMM/AMN eyes and healthy control eyes
PLEX Elite 9000 (Carl Zeiss AG, Dublin, CA)
Copernicus REVO (software Version 7.2; Optopol,

Zawiercie, Poland)
OCTA revealed choriocapillaris flow void that colocalized to the AMN lesions in all affected eyes

Using an automatic algorithm allowed a comparison between the areas of interest of two different imaging modalities using vascular registration OCTA did not reveal low abnormalities within the DCP

Persistence of OCTA choroidal flow void after the resolution of the hyperreflectivity of the outer retinal layers Suggestion that decreased flow in choriocapillaris might be the primary insult in AMN, followed by
AngioPlex, Cirrus HD-OCT 5000

(Carl-Zeiss Meditec Inc.) 
Table 1 Summary of publications on the implementation of OCTA in white dot syndromes (Continued)

\begin{tabular}{ll}
\hline Disease & Publication \\
\hline & \\
& \\
& Nemiroff, J., D. Sarraf, J. \\
& P. Davila And D. Rodger \\
& (2018). Optical \\
& coherence tomography \\
& angiography of acute \\
& macular \\
& neuroretinopathy reveals \\
& deep capillary ischemia. \\
& Retin Cases Brief Rep 12 \\
& Suppl 1: S12-S15. \\
& Thanos, A., L. J. Faia, Y. \\
& Yonekawa And S. \\
& Randhawa (2016). \\
& Optical coherence \\
& tomographic \\
angiography in acute & macular \\
neuroretinopathy. Jama & Ophthalmol 134(11): \\
1310-1314.
\end{tabular}

Chu, S., P. L. Nesper, B. T. Soetikno, S. J. Bakri And A. A. Fawzi (2018).

Projection-resolved OCT angiography of microvascular changes in paracentral acute middle maculopathy and acute macular neuroretinopathy. Invest Ophthalmol Vis Sci 59(7): 2913-2922.
2 eyes of 1 patient (1 eye with macular lesion)

3 eyes of 2 patients Case reports
22 eyes of 21 being excluded (5 eyes with AMN and 13 eyes with PAMM)
Single case report

(n)

Retrospective case series

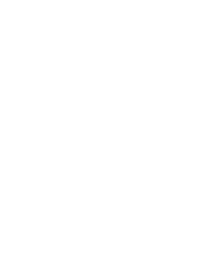

Pecen, P. E., A. G. Smith And J. P. Ehlers (2015). Optical coherence tomography angiography of acute macular neuroretinopathy and

2 eyes of 1 patient Single case report
(1 eye
lesion) patients patients with 4 eye

Main results and points

OCTA device

of discussion

hypoxic insult to the middle, then outer retina

OCTA showed flow deficit at the level of the DCP corresponding to the AMN lesion and OCT imaging

Optovue Avanti-RTVue-XR (Optovue, Fremont, California, USA)

OCTA did not reveal

OCTA device of Carl Zeiss DCP nor SCP flow loss in AMN lesions

Choriocapillaris flow abnormalities colocalised with the OCT alterations of the outer nuclear layer and ellipsoid zone identified with en face OCT, but were larger Suggestion that a vascular insult in the choriocapillaris is the pathogenic mechanism of the AMN lesions

On OCTA, PAMM lesions were associated with reduced $M C P$ and $D C P$ flow signals with partially additional reduced flow signal in the SCP

PAMM eyes without later reperfusion of the MCP showed more severe inner nuclear layer thinning AMN lesions were associated with reduced DCP flow signals Conclusion that isolated focal DCP ischemia at the photoreceptor axons in the OPL is the trigger for AMN pathology, thereby leading to longterm outer nuclear layer thinning

All AMN and PAMM lesions had evidence of variable recovery of capillary flow signal at the different capillary level

OCTA showed capillary nonperfusion correlating with subsequent inner nuclear layer atrophy in the presented case of PAMM

OCTA could be used to
Optovue Avanti-RTVue-XR (Optovue, Fremont, California, USA)
Spectral-domain-OCTA, no details available
Meditec, no details available

.


Table 1 Summary of publications on the implementation of OCTA in white dot syndromes (Continued)

\begin{tabular}{|c|c|c|c|c|c|}
\hline Disease & Publication & $\begin{array}{l}\text { Number of eyes/ } \\
\text { patients }\end{array}$ & Study type & $\begin{array}{l}\text { Main results and points } \\
\text { of discussion }\end{array}$ & OCTA device \\
\hline & $\begin{array}{l}\text { paracentral acute middle } \\
\text { maculopathy. Jama } \\
\text { Ophthalmol 133(12): } \\
\text { 1478-1480. }\end{array}$ & & & $\begin{array}{l}\text { differentiate laminar } \\
\text { focal capillary defects } \\
\text { that may be undetected } \\
\text { by FA or when FA is not } \\
\text { applicable for medical } \\
\text { reasons in AMN and } \\
\text { PAMM }\end{array}$ & \\
\hline \multirow[t]{3}{*}{ AZOOR } & $\begin{array}{l}\text { Levison, A. L., K. Baynes, } \\
\text { C. Y. Lowder And S. K. } \\
\text { Srivastava (2016). OCT } \\
\text { angiography } \\
\text { identification of } \\
\text { choroidal } \\
\text { neovascularization } \\
\text { secondary to acute } \\
\text { zonal occult outer } \\
\text { retinopathy. Ophthalmic } \\
\text { Surg Lasers Imaging } \\
\text { Retina 47(1): } 73-75 .\end{array}$ & 1 eye of 1 patient & Single case report & $\begin{array}{l}\text { Distinctive changes } \\
\text { identified on OCTA } \\
\text { aided in the diagnosis } \\
\text { and management of } \\
\text { CNV in AZOOR } \\
\text { Suggestion that OCTA } \\
\text { can be useful in } \\
\text { distinguishing } \\
\text { inflammatory changes } \\
\text { versus neovascular } \\
\text { changes in patients with } \\
\text { posterior uveitis }\end{array}$ & $\begin{array}{l}\text { Optovue Avanti-RTVue-XR } \\
\text { (Optovue, Fremont, California, } \\
\text { USA) }\end{array}$ \\
\hline & $\begin{array}{l}\text { Mehrotra, N., M. Nagpal, } \\
\text { J. Khandelwal And R. } \\
\text { Juneja (2018). Panoramic } \\
\text { Optical Coherence } \\
\text { Tomography } \\
\text { Angiography Features In } \\
\text { Acute Zonal Occult } \\
\text { Outer Retinopathy. } \\
\text { Indian J Ophthalmol } \\
\text { 66(12): 1856-1858. }\end{array}$ & 2 eyes of 1 patient & Single case report & $\begin{array}{l}\text { Panoramic OCTA } \\
\text { showed increased } \\
\text { decorrelation signal at } \\
\text { the DCP in the } \\
\text { watershed zone of } \\
\text { AZOOR lesions }\end{array}$ & $\begin{array}{l}\text { RS-3000 Advance OCT (Nidek, } \\
\text { Japan) }\end{array}$ \\
\hline & $\begin{array}{l}\text { Naik, A. U., N. } \\
\text { Ezhilvathani And J. } \\
\text { Biswas (2018). Acute } \\
\text { zonal occult outer } \\
\text { retinopathy: is optical } \\
\text { coherence tomography } \\
\text { angiography useful? } \\
\text { Indian J Ophthalmol } \\
66(11): \text { 1637-1639. }\end{array}$ & 2 eyes of 1 patient & Single case report & $\begin{array}{l}\text { En-face OCTA images } \\
\text { demonstrated } \\
\text { hyperreflective dot } \\
\text { structures at at the level } \\
\text { of ellipsoid zone at } \\
\text { presentation } \\
\text { Vasculature of the SCP, } \\
\text { DCP, choriocapillaris, } \\
\text { and the choroid at } \\
\text { presentation and over } \\
\text { two consecutive } \\
\text { monthly follow-ups was } \\
\text { within normal limits } \\
\text { Rise of question, } \\
\text { whether AZOOR was } \\
\text { part of pachychoroid } \\
\text { spectrum } \\
\text { Speculation that the en- } \\
\text { face OCTA findings } \\
\text { might represent the de- } \\
\text { generating photorecep- } \\
\text { tor segments }\end{array}$ & $\begin{array}{l}\text { AngioPlex (Carl Zeiss Meditec } \\
\text { Inc., Dublin, CA, USA) }\end{array}$ \\
\hline Miscellaneous & $\begin{array}{l}\text { Wang Jc, Lains I, Sobrin } \\
\text { L, Miller Jb. } \\
\text { Distinguishing White } \\
\text { Dot Syndromes Aith } \\
\text { Patterns of Choroidal } \\
\text { Hypoperfusion on } \\
\text { Optical Coherence } \\
\text { Tomography } \\
\text { Angiography. } \\
\text { Ophthalmic Surg Lasers } \\
\text { Imaging Retina. } \\
\text { 2017;48(8):638-46. }\end{array}$ & $\begin{array}{l}7 \text { eyes of } 4 \text { patients } \\
\text { with different WDS } \\
\text { (APMPPE, BCR, } \\
\text { MEWDS, POHS) }\end{array}$ & Case reports & $\begin{array}{l}\text { APMPPE: hypoperfusion } \\
\text { was more pronounced } \\
\text { in the choriocapillaris } \\
\text { than in the deeper } \\
\text { choroid in OCTA and } \\
\text { more widespread than } \\
\text { the retinal lesions } \\
\text { BCR: abnormalities in } \\
\text { perfusion, that were } \\
\text { more pronounced in the } \\
\text { choroid than in the } \\
\text { choriocapillaris; smaller } \\
\text { areas of choroidal } \\
\text { hypoperfusion did not }\end{array}$ & $\begin{array}{l}\text { AngioPlex OCT Angiography } \\
\text { (Carl Zeiss AG, Oberkochen, } \\
\text { Germany) } \\
\text { or } \\
\text { Optovue Avanti-RTVue-XR } \\
\text { (Optovue, Fremont, California, } \\
\text { USA) }\end{array}$ \\
\hline
\end{tabular}


Table 1 Summary of publications on the implementation of OCTA in white dot syndromes (Continued)

\begin{tabular}{|c|c|c|c|c|c|}
\hline Disease & Publication & $\begin{array}{l}\text { Number of eyes/ } \\
\text { patients }\end{array}$ & Study type & $\begin{array}{l}\text { Main results and points } \\
\text { of discussion }\end{array}$ & OCTA device \\
\hline & & & & $\begin{array}{l}\text { have corresponding } \\
\text { fundus lesions making } \\
\text { OCTA probably a more } \\
\text { sensitive diagnostic tool } \\
\text { for early lesions } \\
\text { MEWDS: well- } \\
\text { demarcated focal areas } \\
\text { of hypoperfusion in the } \\
\text { choriocapillaris of larger } \\
\text { lesions corresponded } \\
\text { well to the white dots, } \\
\text { which supports the hy- } \\
\text { pothesis that the outer } \\
\text { retina is the location of } \\
\text { primary pathology } \\
\text { POHS: focal injury } \\
\text { appeared to occur in } \\
\text { POHS as opposed to } \\
\text { more widespread } \\
\text { immune response in } \\
\text { BCR, APMPPE, and } \\
\text { MEWDS. OCTA revealed } \\
\text { the correlation between } \\
\text { the "punched out" } \\
\text { lesions of POHS and } \\
\text { hypoperfusion of } \\
\text { choriocapillaris and } \\
\text { choroid } \\
\text { OCTA revealed } \\
\text { hypoperfusion of the } \\
\text { choriocapillaris and } \\
\text { choroid as a shared } \\
\text { feature among different } \\
\text { white dot syndromes } \\
\text { and the differences in } \\
\text { the distribution, depth, } \\
\text { and extend of these } \\
\text { OCTA changes may aid } \\
\text { in diagnosis }\end{array}$ & \\
\hline
\end{tabular}

Mangeon M, Zett C,

Amaral C, Novais E,

Muccioli C, Andrade G,

Et Al. Multimodal

evaluation of patients

with acute posterior

multifocal placoid

pigment epitheliopathy

and serpiginous

choroiditis. Ocular

Immunology And

Inflammation.

2018;26(8):1212-18.
8 eyes of 4 patients Case reports

(6 eyes with

serpiginous

choroiditis and two

eyes with acute

posterior multifocal

placoid pigment

epitheliopathy)
Optovue Avanti-RTVue-XR

(Optovue, Fremont, California, USA)
PMPPE: OCTA showed despite of the stage of disease, choriocapillaris hypoperfusion, but partial reperfusion in the choriocapillaris 2 months after treatment in one case

Serpiginous choroiditis: OCTA allowed the diagnosis of CNV; RPE atrophy (as clarified on OCT and FAF) corresponded to localized OCTA

hypoperfusion pattern of the choriocapillaris, which could generate a quantitative parameter usable for follow-up

$A M N$ acute macular neuroretinopathy, anti-VEGF anti-vascular endothelial growth factor, $A P M P P E$ acute posterior multifocal placoid pigmentepitheliopathy, $A Z O O R$ acute zonal occult outer retinopathy, $B S R$ birdshot chorioretinopathy, $C N V$ choroidal neovascularization, $D C P$ deep capillary plexus, $F A$ fluorescein angiography, $F A F$ fundus autofluorescence, ICG indocyanine green, ICGA indocyanine green angiography, MEWDS multiple evanescent white dot syndrome, MCP multifocal choroiditis and panuveitis, OCT optical coherence tomography, OCTA optical coherence tomography angiography, PAMM paracentral acute middle maculopathy, PIC punctate inner choroidopathy, $P O H S$ presumed ocular histoplasmosis syndrome, RPE retinal pigment epithelium, SCP superficial capillary plexus, SD-OCTA spectral domain OCTA, SS-OCTA swept-source OCTA 


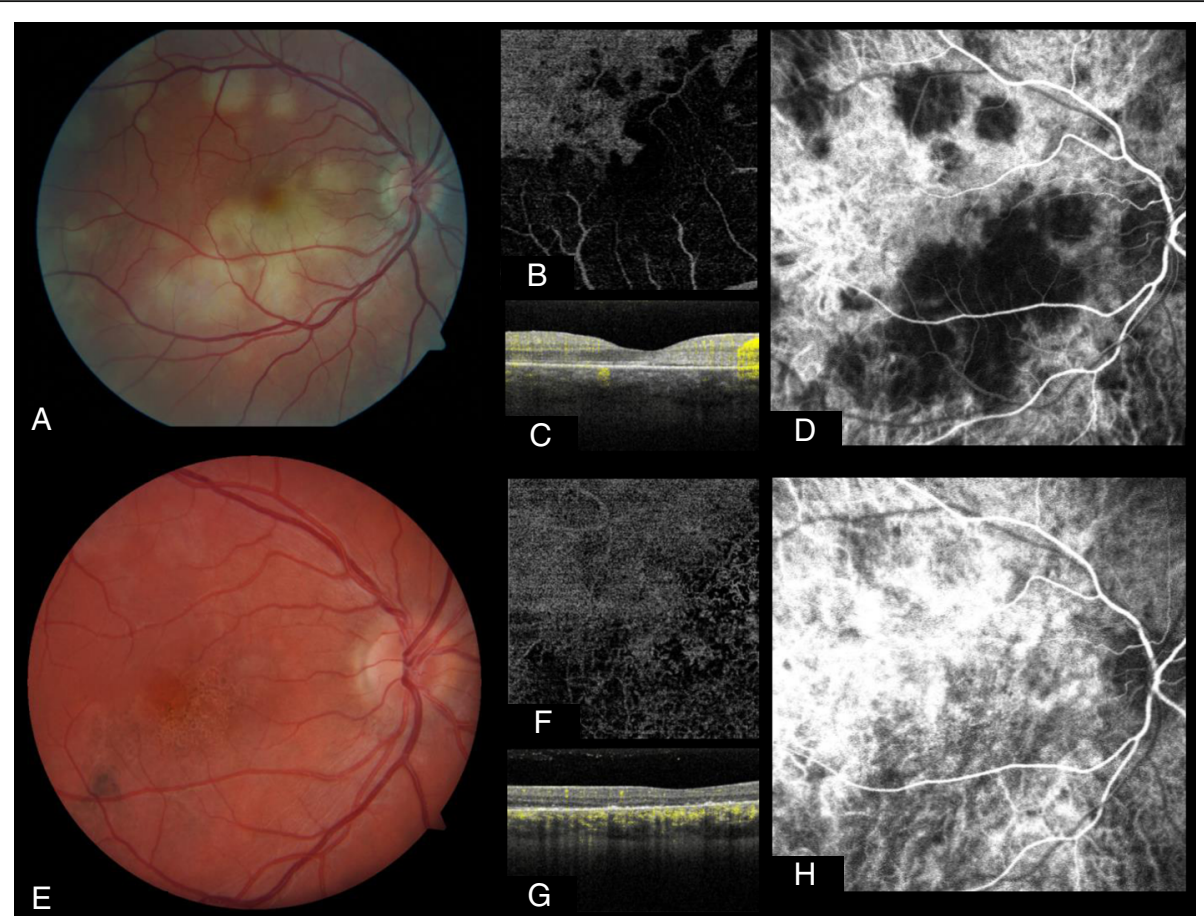

Fig. 3 Multimodal imaging analysis of the macular and peripapillary area of the right eye showing multiple lesions at different stages of acute posterior multifocal placoid pigment epitheliopathy (APMPPE). Images $\mathbf{a}, \mathbf{b}, \mathbf{c}$ and $\mathbf{d}$ were taken 3 days after onset of symptoms. a Color image of the fundus showing fresh lesions. b En face reconstruction of the choriocapillaris flow by optical coherence tomography angiography (OCTA) demonstrating an area of lacking signal. c Structural OCT with superimposed flow signal revealing areas with decreased flow signal. d Early phase indocyanine green angiography (IA) with a hypocyanescent area corresponding to clinically visible early lesions. Images $\mathbf{e}, \mathbf{f}, \mathbf{g}$, and $\mathbf{h}$ were taken 6 months after the onset of symptoms. e Color image of the fundus showing old macular lesions. $\mathbf{f}, \mathbf{g}$ En face reconstruction of the choriocapillaris flow by OCTA demonstrating an increased area of low signal compared to $\mathbf{b}$ and $\mathbf{c}$, respectively. $\mathbf{g}$ Structural OCT with superimposed flow signal revealing an increase of low signal compared to $\mathbf{c}$. $\mathbf{h}$ Early-phase IA showing almost no sign of the hypocyanescent area seen in $\mathbf{d}$

In FA, acute lesions show early hypofluorescence and late leakage and staining at lesions' border. Older lesions present with window defect, and, in case of progress or relapse, with staining along the progressing edges. ICGA has been used for staging and detecting new activity during the course of the disease. The area of hypocyanescent choroidal non-perfusion is usually larger than expected by fundus examination, and OCTA can be used in serpiginous choroiditis to detect subclinical or persistent choroidal nonperfusion as lesion size on the OCTA choriocapillaris slabs shows a good correlation with lesions on ICGA [64]. In active disease, the flow void area of the choriocapillaris slabs not associated with corresponding abnormal autofluorescence on FAF resolve without sequela [65].

As reported in another retrospective study with 22 eyes and case series of six eyes, there was no flow signal throughout the entire choroid in active lesions, whereas in inactive lesions, OCTA signals indicated some hyperintensity, which is interpreted as rarefaction of choroidal vessels and loss of choriocapillaris $[60,66]$.

\section{Multiple evanescent white dot syndrome (MEWDS)}

OCTA also helped to get a better understanding of the pathogenesis of MEWDS. In contrast to serpiginous choroiditis and APMPPE, OCTA revealed that the choriocapillaris is not involved in MEWDS. MEWDS is characterized by gray-white fundus lesions, which are the result of RPE lesions, typically located outside the fovea in a granular pattern. Rare findings can be sheathing of retinal veins and superficial retinal hemorrhages.

In MEWDS lesions, an early wreath-like hyperfluorescence of the smaller "dots" and late staining of larger "spots" on FA can be seen.

On FAF images, hyperautofluorescent dots can be appreciated even when funduscopy does not correlate with these dots. On ICGA, the early phase is unremarkable, but in the late phase, multifocal hypocyanescent lesions, even in clinically inconspicuous areas, with ill-defined margins, characterize the lesions of MEWDS. Looking at the unremarkable choriocapillaris of OCTA findings in MEWDS, hypocyanescence in ICGA could no longer be interpreted as changes of choroidal vascularity, but 
supported the thesis of Chang et al., mentioned above, that under physiological conditions, RPE normally absorbs ICG, causing physiological background hypercyanescence, and thus, it has been hypothesized that in MEWDS, the RPE is primarily affected and that ICGA uptake is interrupted by diseased RPE [21, 25, 67-69]. However, in larger lesions of MEWDS, reduced flow of choriocapillaris had also been detected, thus ICGA hypocyanescence may be still interpreted as a reduction of choroidal blood flow [70]. However, altered flow information may be also due to a change in the optical property of the choroid due to blockage of invading inflammatory cells. Once again, the limitation of OCTA in detecting flow in the slow-flow system of the choriocapillaris with high enough sensitivity needs to be taken into account [71].

Remarkably, in the light of OCTA findings in this uveitis type, the discussion about the pathogenesis of MEWDS was recently risen up and mainly questions the primary focus of inflammation, be it in the RPE or the choriocapillaris [70].

\section{Multifocal choroiditis and panuveitis (MCP)}

MCP, a chronic, recurrent disease, typically affects female patients in their fourth decade of life. Multiple yellow or yellowish gray lesions of various size, primarily at the level of the RPE and inner choroid, in association with vitreous cells, can be seen on funduscopy.

In their inactive form, these lesions appear punched out, possibly with pigmented fraction and scarring. A common complication in MCP is an inflammatory CNV of type 2 and, as already noted above, OCTA can be very helpful in these cases to define and detect inflammatory CNVs, which is essential for further treatment decisions $[15,19,54,55,57,72]$ (Fig. 4).

But OCTA has also been shown to have limitations in differentiating active neovascularization versus an inactive scar [57]. Again, the result of an OCTA examination cannot be interpreted without considering conventional OCT and dye-based imaging techniques.

\section{Punctate inner choroidopathy (PIC)}

Similarly to MCP, PIC is a condition in which early detection of new and progressing inflammatory CNV is of high relevance, as the development of macular or foveal $\mathrm{CNV}$ in PIC is a common complication, even more common than in MCP. In contrast to MCP, PIC rarely is associated with vitritis and lesions are less commonly seen anterior to the posterior pole and are rather scattered than arranged in a particular pattern. Similarly to MCP, it has been reported that OCTA can detect inflammatory CNV, when FA may be not conclusive due to a similar appearance of a type $2 \mathrm{CNV}$ and an active lesion $[15,19,54,57,73]$.

\section{Presumed ocular histoplasmosis syndrome (POHS)}

OCTA reports on POHS are very rare [70, 74]. POHS is characterized by multiple white atrophic chorioretinal scars or spots, so-called "histo-spots," peripapillary atrophy and the absence of vitritis. It may be associated with CNV. Sixty percent of the cases are bilateral. POHS lesions correspond to areas of focal flow loss in the choriocapillaris and deeper choroidal layers on OCTA, which is consistent with the theory that choroidal seeding of Histoplasma capsulatum spores leads to the destruction of choroidal blood vessels [70].

In contrast to most other white dot syndromes, the lesions are more focal than widespread. Only one case of $\mathrm{CNV}$ due to POHS based on OCTA evolution has been published until today, and it has been suggested that, in POHS, OCTA might be more sensitive than FA or OCT in detecting very early increase or recurrence of $\mathrm{CNV}$ activity [74].

\section{Birdshot retinochoroidopathy (BSR)}

The name BSR was given to this form of white dot lesion due to its shotgun pattern of creamy whitish lesions scattered throughout the fundus. It is strongly associated with HLA-29 and presents with moderate vitritis and phlebitis, and the lesions affect the choroid and the retina. In a prospective observational review of four patients with BSR, OCTA visualized telangiectasia, capillary dilatations and loops, and an increased intercapillary space in the retinal vasculature [75]. Moreover, looking at the SCP in birdshot patients, OCTA showed a larger area of FAZ than previously supposed using FA [19]. Furthermore, as central retinal thinning in birdshot patients correlates with these areas displaying a decreased capillary perfusion on OCTA, it was postulated that thinning of the macula could be due to an ischemic insult to ganglion cells and their axons, although macular thinning on OCT scans show mainly a thinning of outer retinal layers [19]. Looking at the DCP, even more reduction of flow could be detected, which was proposed to be, besides inflammatory reasons, a possible explanation for the development of retinal neovascularization in BSR [76] (Fig. 1).

OCTA demonstrates multifocal hypoperfusion within the choriocapillaris and even larger areas of hypoperfusion when looking at deeper choroidal layers [70, 75]. Early active lesions are found in near vicinity of the larger vessels of the Haller layer [68]. While early active lesions may only involve the deeper choroidal layers and may regress under treatment, chronic birdshot lesions will reveal full thickness choroidal flow void also affecting the choriocapillaris. These lesions will not regress under appropriate treatment [77]. Based on these findings, OCTA may be a reliable additional tool to follow 

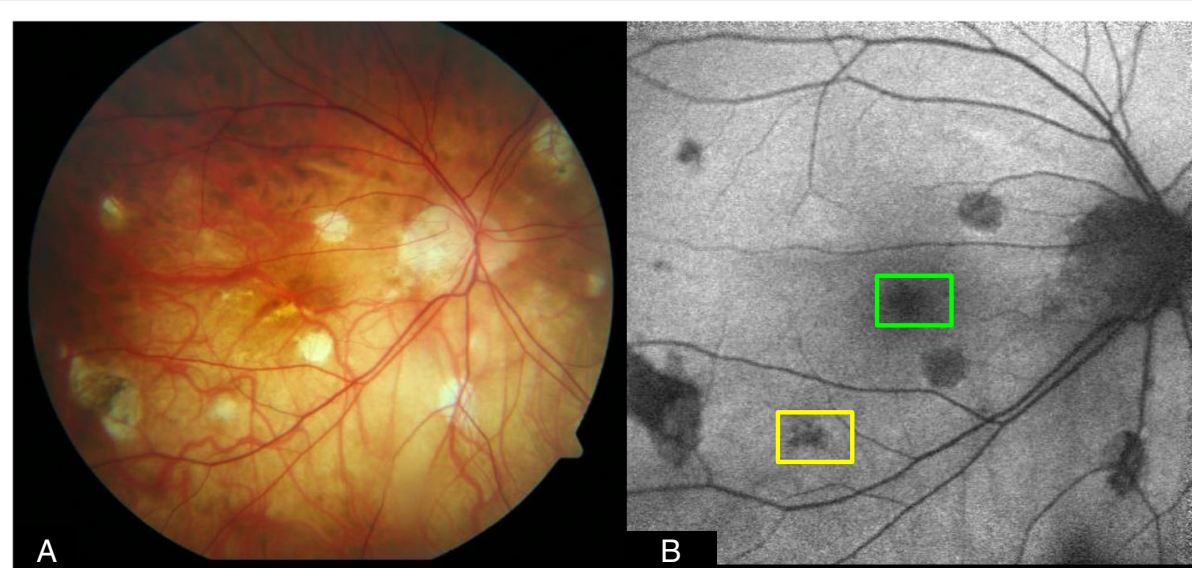

B

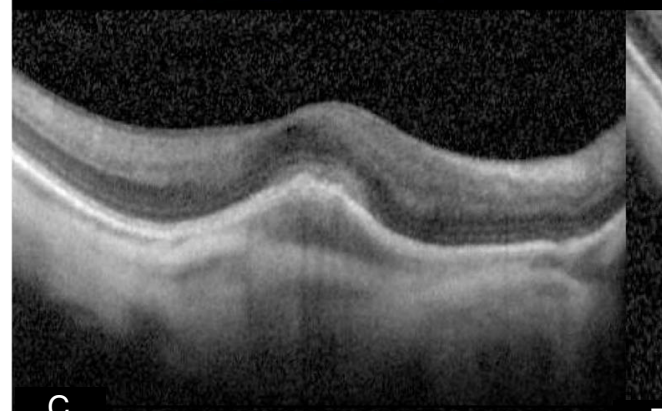

$\mathbf{F}$

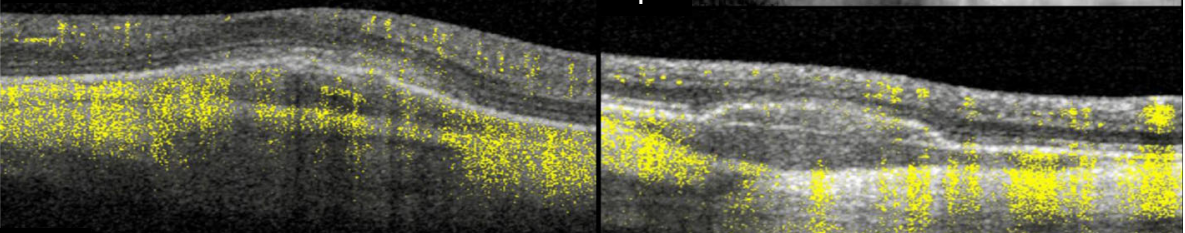

G

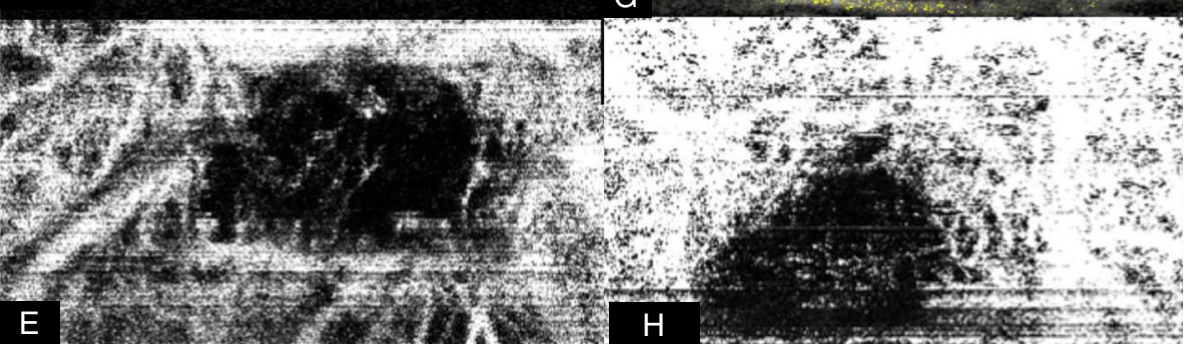

Fig. 4 Optical coherence tomography angiography (OCTA) for differentiating acute inflammatory lesions from choroidal neovascularization in a myopic eye with idiopathic multifocal choroiditis. a Color photograph shows multiple yellowish-gray lesions perifoveolar and nasal the optic nerve head. $\mathbf{b}$ Fundus autofluorescence in this case shows unspecific mottled hypoautofluorescence of the lesions. c Structural OCT scan over the lesion within the green box in panel B shows hyperreflective material below and minimal above the retinal pigment epithelium (RPE). $\mathbf{d}$ Cross-sectional OCTA of the same lesion demonstrates slightly abnormal flow above the RPE, representing type 2 neovascularization. e En face OCTA reconstruction, which shows a small choroidal neovascularization. $\mathbf{f}$ Structural OCT scan over the lesion within the yellow box in panel $\mathbf{b}$ shows hyperreflective material below the RPE and a well-defined Bruch's membrane. $\mathbf{g}$ Cross-sectional OCTA shows the absence of abnormal flow beneath the RPE. The flow overlying the RPE layer represents the projection of the flow signal from the more superficial retinal circulation (projection artifact). $\mathbf{h}$ En face OCTA reconstruction. It looks like vascular branches of a choroidal neovascularization, but scrolling the slap through the retina represents a projection artifact

birdshot patients and to identify disease progression and insufficient treatment [77].

\section{Acute macular neuroretinopathy (AMN)}

$\mathrm{AMN}$ is characterized as wedge-shaped superficial retinal defects in the macula, resulting in paracentral scotomas and are associated with vasoconstrictors and sympathomimetics. The fact that a majority of patients are young females and a lot report flu-like symptoms prior onset of eye symptoms has prompted the conclusion that AMN belongs to the spectrum of white dot syndromes. On OCT, AMN starts with hyperreflectivity of the outer 
plexiform layer with subsequent thinning of the outer nuclear layer and a significant attenuation of the interdigitation zone (IZ) and ellipsoid zone and external limiting membrane. Changes resolve over time; however, usually, sequelae of IZ attenuation, photoreceptor layer thinning, and corresponding scotomas remain. In various case reports or series, OCTA examination revealed a flow void in the DCP $[78,79]$. However, some case series also found persistent flow attenuation in the choriocapillaris $[78,80$, 81]. While paracentral acute middle maculopathy (PAMM) shows consistently flow changes in the DCP as well as the middle capillary plexus and occasionally also in the SCP throughout the literature, the changes found in AMN are more inconsistent [82-85]. Based on these findings, it is hypothesized that the location of primary insult in AMN is located in the DCP [84]. In contrast to AMN, PAMM is often associated with cardiovascular diseases and cardiovascular risk factors and should therefore not be restricted to the white dot spectrum $[81,86]$.

\section{Acute zonal occult outer retinopathy (AZOOR)}

AZOOR is a rare retinopathy that, in some cases with preceding viral infection, affects one eye, but may also progress to involvement of the second eye. Intraocular cells are rare and the fundus in the early phase appears normal. As the disease progresses, decreased vision and photopsia is realized by the patient, and a scotoma coinciding with the affected zone of outer retinal dysfunction, often an enlargement of the blind spot, is detectable. The typical finding in progressing AZOOR lesions is retinal atrophy and mottling of the RPE leading to typical fundus changes with grayish or yellowish lines along the atrophy area of the RPE, outer retina, and choroid. FAF illustrates a characteristic trizonal sign with the increased autofluorescence of active lesions and decreased autofluorescence of damaged RPE cells and normal autofluorescence of the unaffected retina. ICGA may be normal or show hypocyanescence. FA shows, later in the course of the disease, window defects. OCTA findings may show increased decorrelation signal at the DCP at the watershed zone [87], but at early presentation, a case report demonstrated normal OCTA imaging of the retinal and choroidal vasculature, whereas en face OCTA structural analysis revealed hyper-reflective dots at the level of ellipsoid zone of different patterns in both affected eyes of one patient [88].

\section{About optical coherence tomography angiography in infectious uveitis}

Most existing OCTA reports on infectious uveitis types are related to tuberculosis (TB)-associated uveitis. Furthermore, there are some reports on toxoplasmosis, acute retinal necrosis (ARN), and more infrequent conditions such as dengue fever, Bartonella (cat-scratch disease) and West Nile virus infection, which will be summarized below.

\section{Intraocular tuberculosis (TB)}

TB has various forms of appearance: granulomatous anterior uveitis, intermediate uveitis, panuveitis or posterior uveitis, the latter being the most common presentation. Diverse clinical findings can be seen in TB, e.g., granulomata, occlusive retinal vasculitis, or serpiginous-like choroiditis or multifocal serpiginoid choroiditis [89]. In TB, OCTA has proven to be useful in the detection of CNV in a patient with tubercular serpiginous-like choroiditis and showed an involvement of various retinochoroidal layers by an abnormal vascular network [90].

In serpiginous-like TB chorioretinitis, OCTA showed a more precise picture of choroidal hypoperfusion as compared with ICGA [89] and was useful in the follow-up of patients with tubercular multifocal serpiginoid choroiditis [91].

In a case report of choroidal granuloma caused by TB, a type $2 \mathrm{CNV}$ could be detected in its early stage, and growth was documented with the help of OCTA, although secondary complications like intraretinal fluid were not yet found [52].

In a sample of nine eyes with different forms of posterior tuberculous uveitis, OCTA showed neovascular flow assigned to type $1 \mathrm{CNV}$ [53].

For longitudinal choriocapillaris flow evaluation in a TB patient with serpiginous-like choroiditis, OCTA showed progressive restoration of the choroidal circulation over time, with reduction of the lesion size and reduction in hypoperfusion, suggesting vascular remodeling during the recovery phase [92]. The choriocapillaris flow appeared to progressively restore centrally from the lesion edges under treatment, correlating with FAF signal changes over time, which is an interesting and similar finding as in APMPPE and in idiopathic serpiginous chorioretinopathy [92]. These findings were confirmed in a larger prospective case series of 32 eyes using a panoramic OCTA device [93].

\section{Toxoplasmosis}

The parasite Toxoplasma gondii, an intracellular protozoan, causes necrotizing retinochoroiditis and can cause severe vision loss. A possible complication is CNV, which can be detected quite easily with OCTA (Fig. 2). A double case report about $\mathrm{CNV}$ in toxoplasmosis confirmed the utility of OCTA for CNV secondary to ocular toxoplasmosis, especially, as FA can be difficult to interpret in a scarred area [94].

Another, less recent case report focused on the advantage of volume rendering on OCTA of such lesions, 
which allows visualization of all OCTA scans simultaneously [95].

A new case report used OCTA for longitudinal follow-up of a toxoplasmic lesion and showed vascular obliteration of the retina and choroid in the acute stage with only partial restoration in the periphery of the lesion during the quiescent stage, but with persistence of destruction in the choriocapillaris texture [96].

\section{Herpesviridae}

Acute retinal necrosis (ARN), mainly caused by varicella zoster virus and herpes simplex virus types 1 and 2 , is characterized by vitreal and anterior chamber inflammatory reaction, retinal necrotic lesions, circumferential progression, and evidence of occlusive vasculopathy. A recent case report suggested that OCTA could be used in ARN cases to evaluate the therapeutic response and anatomical improvement as macular vascular density has been observed to decrease until normal density is restored within one month in the SCP and DCP during therapy, supplied by capillary branches of the vessel embedded in a necrotizing retinal lesion [97].

\section{Dengue fever}

Dengue fever, an arthropod-borne disease, caused by four serotypes of Dengue virus, can manifest various ophthalmologic symptoms, such as subconjunctival hemorrhage, keratitis, anterior uveitis, angle-closure glaucoma as for anterior segment and, more commonly, ME, retinal hemorrhages, foveolitis, cotton wool spots, AMN lesions, and microaneurysms as for posterior segment involvement [98]. Deduced from case reports, OCTA has proven to be a worthy diagnostic tool for detecting flow deficits in the perifoveal region within the DCP and SCP in ischemic inflammatory foveolitis and outer maculopathy, even when fundus lesions were not detectable [98-100].

\section{Cat-scratch disease}

Bartonella henselae causes focal retinochoroiditis, Parinaud oculoglandular syndrome and neuroretinitis. Bartonella bacteria tend to colonize endothelial cells which seem to have vasoproliferative effects and local CNV-development [101]. The case of one patient with Bartonella-associated CNV was investigated with OCTA, which proved to be helpful, since dye-based angiographies could not be interpreted conclusively as the hyperfluorescence of the inflammatory lesion did not allow the differentiation of a local neovascular complex [101].

\section{West Nile virus (WNV)}

West Nile virus (WNV) infection of the eye is mostly associated with bilateral multifocal chorioretinitis. Vascular involvement has also been described, including retinal hemorrhages, retinal vascular sheathing, retinal vascular leakage on FA, and, rarely, mostly in patients of advanced age with diabetes, occlusive retinal vasculitis. Of the latter form, one case report, already mentioned above, has been published, and the authors claimed the superiority of OCTA to FA for detecting ischemic retinal capillary changes, allowing a differentiation between involvement of the SCP and the DCP, with the latter one being more involved, as also described earlier in the case of BSR and Behçet's uveitis [45-47]. While during follow-up, funduscopic lesions diminished, retinal capillary nonperfusion on OCTA persisted [45].

\section{Conclusion}

In recent years, many articles about the application of OCTA in eyes with various forms of uveitis have been published, with a major part of them being case reports or case series. Obviously, the problem is twofold. First, specific algorithms to interpret specific issues need to be developed to make its use more attractive for clinicians. Second, OCTA has not yet been established in the daily routine of ophthalmologists, suggesting that the development and implementation of such algorithms will be slow, as is to be expected with a newly introduced diagnostic tool. The latter reason might also be due to the fact that knowledge and understanding of artifacts is required in order to enable the clinician to make valid interpretations of the OCTA images, even though the handling and transposition per se could be well suited for daily use.

The use of OCTA in inflammatory CNV, for example, seems to be one of the easier parts for interpretation, which is natural given inflammatory $\mathrm{CNV}$ being a lesion of many uveitis types and also the widespread use of OCTA in AMD related CNV. However, the number of various uveitis cases will not easily allow larger sample size studies.

A good example of this problem is white dot syndromes. Here, studying their different subtypes, specifically with OCTA, is challenging because of their fairly rare prevalence. However, OCTA might be of great relevance, as their classification system and, in some cases also the theory about their pathogenesis, might have to be re-evaluated.

In summary, OCTA can be seen as a complementary diagnostic tool in uveitis, which, in some cases, can highlight pathology earlier in the course of the disease than traditional imaging tools and sometimes gives an indication of the affected layers in or under the retina, which were formerly not detectable. Of course, the awareness of typical artifacts should always be kept in mind during the interpretation of the images, and future studies with larger sample sizes should aim at elaborating on further disease-specific algorithms. 


\section{Abbreviations}

AMN: Acute macular neuroretinopathy; anti-VEGF: Anti-vascular endothelial growth factor; APMPPE: Acute posterior multifocal placoid pigmentepitheliopathy; ARN: Acute retinal necrosis; AZOOR: Acute zonal occult outer retinopathy; BSR: Birdshot chorioretinopathy; CNV: Choroidal neovascularization; DCP: Deep capillary plexus; DSF: Diffuse subretinal fibrosis; EDI-OCT: Enhanced depth imaging-OCT; FA: Fluorescein angiography; FAF: Fundus autofluorescence; ICG: Indocyanine green; ICGA: Indocyanine green angiography; IU: Intermediate uveitis; IZ: Interdigitation zone; MCP: Multifocal choroiditis and panuveitis; ME: Macular edema; MEWDS: Multiple evanescent white dot syndrome; OCT: Optical coherence tomography; OCTA: Optical coherence tomography angiography; PAMM: Paracentral acute middle maculopathy; PIC: Punctate inner choroidopathy; POHS: Presumed ocular histoplasmosis syndrome; RPE: Retinal pigment epithelium; SCP: Superficial capillary plexus; SDOCTA: Spectral domain OCTA; SS-OCTA: Swept-source OCTA; SSPiM: Suspended scattering particles in motion; TB: Tuberculosis; VKH: Vogt-Koyanagi-Harada disease; WNV: West Nile Virus

\section{Acknowledgements}

We wish to acknowledge the contribution to this review provided by our team of study coordinators.

\section{Funding}

This review was supported by the "Stiftung wissenschaftliche Forschung, Fonds Ophthalmologie am Stadtspital Triemli" and the "Werner H. Spross Foundation zur Förderung der Augenheilkunde". Both funding organizations had no role in the design of this review.

\section{Availability of data and materials}

Not applicable

\section{Authors' contributions}

VLSD contributed to the drafting and design of the manuscript. SK, MPB, FH, and VLSD interpreted and designed the patients' multimodal images presented in this review. SL, SO, and FF contributed to the revision of the manuscript. MB and MRM contributed to the acquisition of data and revision of the manuscript. All authors read and approved the final manuscript.

\section{Ethics approval and consent to participate}

According to the statement of the cantonal ethics committee, this review does not fall within the scope of the Human Research Act (HRA), and therefore, an authorization is not required (reference number: 2019-00152).

\section{Consent for publication}

All four patients gave their written consent to publish their image material.

\section{Competing interests}

The authors declare that they have no competing interests.

\section{Publisher's Note}

Springer Nature remains neutral with regard to jurisdictional claims in published maps and institutional affiliations.

\section{Author details}

'Department of Ophthalmology, City Hospital Triemli, Birmensdorferstrasse 497, CH-8063 Zürich, Switzerland. 'Department of Ophthalmology, University Clinic Bern, Bern, Switzerland. ${ }^{3}$ Department of Ophthalmology, University of Heidelberg, Heidelberg, Germany.

Received: 16 March 2019 Accepted: 6 May 2019

Published online: 28 May 2019

\section{References}

1. White $B$ et al (2003) In vivo dynamic human retinal blood flow imaging using ultra-high-speed spectral domain optical coherence tomography. Opt Express 11(25):3490-3497

2. Kim DY et al (2013) Optical imaging of the chorioretinal vasculature in the living human eye. Proc Natl Acad Sci U S A 110(35):14354-14359
3. Zhang A et al (2015) Methods and algorithms for optical coherence tomography-based angiography: a review and comparison. J Biomed Opt 20(10):100901

4. Lipson BK, Yannuzzi LA (1989) Complications of intravenous fluorescein injections. Int Ophthalmol Clin 29(3):200-205

5. Spaide RF, Klancnik JM Jr, Cooney MJ (2015) Retinal vascular layers imaged by fluorescein angiography and optical coherence tomography angiography. JAMA Ophthalmol 133(1):45-50

6. Coscas G, Lupidi M, Coscas F (2016) Image analysis of optical coherence tomography angiography. Dev Ophthalmol 56:30-36

7. Khairallah M et al (2017) Optical coherence tomography angiography in patients with Behcet uveitis. Retina 37(9):1678-1691

8. Spaide RF (2017) Microvascular flow abnormalities associated with retinal vasculitis: a potential of mechanism of retinal injury. Retina 37(6):1034-1042

9. Abucham-Neto JZ et al (2018) Comparison between optical coherence tomography angiography and fluorescein angiography findings in retinal vasculitis. Int J Retina Vitreous 4:15

10. Spaide RF, Fujimoto JG, Waheed NK (2015) Image artifacts in optical coherence tomography angiography. Retina 35(11):2163-2180

11. De Laey JJ (1995) Fluorescein angiography in posterior uveitis. Int Ophthalmol Clin 35(3):33-58

12. de Smet MD, Okada AA (2010) Cystoid macular edema in uveitis. Dev Ophthalmol 47:136-147

13. Gupta V, Al-Dhibi HA, Arevalo JF (2014) Retinal imaging in uveitis Saudi journal of ophthalmology : official journal of the Saudi. Ophthalmological Soc 28(2):95-103

14. Fardeau C et al (2016) Uveitic macular edema. Eye (Lond) 30(10):1277-1292

15. Agarwal A et al (2018) An update on inflammatory choroidal neovascularization: epidemiology, multimodal imaging, and management. J Ophthalmic Inflamm Infect 8(1):13

16. Kempen $\mathrm{JH}$ et al (2013) Fluorescein angiography versus optical coherence tomography for diagnosis of uveitic macular edema. Ophthalmology 120(9): 1852-1859

17. Campbell JP et al (2012) Wide-field retinal imaging in the management of noninfectious posterior uveitis. Am J Ophthalmol 154(5):908-911.e2

18. Mesquida $\mathrm{M}$ et al (2014) Use of ultra-wide-field retinal imaging in the management of active Behcet retinal vasculitis. Retina 34(10):2121-2127

19. Pichi F et al (2017) The application of optical coherence tomography angiography in uveitis and inflammatory eye diseases. Prog Retin Eye Res 59:178-201

20. Kawali A et al (2017) Multimodal imaging of the normal eye. Ocul Immunol Inflamm 25(5):726-736

21. Pichi F et al (2017) Pearls and pitfalls of optical coherence tomography angiography in the multimodal evaluation of uveitis. J Ophthalmic Inflamm Infect 7(1):20

22. Spaide RF et al (1996) Indocyanine green videoangiography of older patients with central serous chorioretinopathy. Retina 16(3):203-213

23. Herbort CP, LeHoang P, Guex-Crosier Y (1998) Schematic interpretation of indocyanine green angiography in posterior uveitis using a standard angiographic protocol. Ophthalmology 105(3):432-440

24. Herbort CP (2009) Fluorescein and indocyanine green angiography for uveitis. Middle East Afr J Ophthalmol 16(4):168-187

25. Chang AA, Zhu M, Billson F (2005) The interaction of indocyanine green with human retinal pigment epithelium. Invest Ophthalmol Vis Sci 46(4):1463-1467

26. Bonte CA, Ceuppens J, Leys AM (1998) Hypotensive shock as a complication of infracyanine green injection. Retina 18(5):476-477

27. Kashani $\mathrm{AH}$ et al (2018) Suspended scattering particles in motion: a novel feature of OCT angiography in exudative maculopathies. Ophthalmol Retina 2(7):694-702

28. Gorczynska I et al (2016) Comparison of amplitude-decorrelation, specklevariance and phase-variance OCT angiography methods for imaging the human retina and choroid. Biomed Opt Express 7(3):911-942

29. Spaide RF et al (2018) Optical coherence tomography angiography. Prog Retin Eye Res 64:1-55

30. Yu S et al (2018) Cataract significantly influences quantitative measurements on swept-source optical coherence tomography angiography imaging. PLoS One 13(10):e0204501

31. Ploner SB et al (2016) Toward quantitative optical coherence tomography angiography: visualizing blood flow speeds in ocular pathology using variable interscan time analysis. Retina 36(Suppl 1):S118-s126 
32. Munk MR et al (2017) OCT-angiography: a qualitative and quantitative comparison of 4 OCT-A devices. PLoS One 12(5):e0177059

33. Corvi F et al (2018) Reproducibility of vessel density, fractal dimension, and foveal avascular zone using 7 different optical coherence tomography angiography devices. Am J Ophthalmol 186:25-31

34. Or C et al (2018) Use of OCTA, FA, and ultra-widefield imaging in quantifying retinal ischemia: a review. Asia Pac J Ophthalmol (Phila) 7(1):46-51

35. Choi WJ, Zhi Z, Wang RK (2014) In vivo OCT microangiography of rodent iris. Opt Lett 39(8):2455-2458

36. Kim AY et al (2016) Quantifying retinal microvascular changes in uveitis using spectral-domain optical coherence tomography angiography. Am J Ophthalmol 171:101-112

37. Ang M et al (2018) Comparison of anterior segment optical coherence tomography angiography systems for corneal vascularisation. $\mathrm{Br} J$ Ophthalmol 102(7):873-877

38. Stanzel, T.P., et al., Comparison of optical coherence tomography angiography to indocyanine green angiography and slit lamp photography for corneal vascularization in an animal model. Sci Rep, 2018. 8(1): p. 11493

39. Roberts PK, Goldstein DA, Fawzi AA (2017) Anterior segment optical coherence tomography angiography for identification of iris vasculature and staging of iris neovascularization: a pilot study. Curr Eye Res 42(8):1136-1142

40. Zett C et al (2018) Comparison of anterior segment optical coherence tomography angiography and fluorescein angiography for iris vasculature analysis. Graefes Arch Clin Exp Ophthalmol 256(4):683-691

41. Wintergerst MWM et al (2018) Optical coherence tomography angiography in intermediate uveitis. Am J Ophthalmol 194:35-45

42. Tian M et al (2018) Evaluation of vascular changes in intermediate uveitis and retinal vasculitis using swept-source wide-field optical coherence tomography angiography. $\mathrm{Br} J$ Ophthalmol. https://doi.org/10.1136/ bjophthalmol-2018-313078

43. Tian M et al (2019) Swept-source optical coherence tomography angiography reveals vascular changes in intermediate uveitis. Acta Ophthalmol. https://doi. org/10.1111/aos.14024

44. Jabs DA, Nussenblatt RB, Rosenbaum JT (2005) Standardization of uveitis nomenclature for reporting clinical data. Results of the first international workshop. Am J Ophthalmol 140(3):509-516

45. Khairallah M et al (2017) Swept-source optical coherence tomography angiography in West Nile virus chorioretinitis and associated occlusive retinal vasculitis. Ophthalmic Surg Lasers Imaging Retina 48(8):672-675

46. Somkijrungroj $T$ et al (2017) Assessment of vascular change using swept-source optical coherence tomography angiography: a new theory explains central visual loss in Behcet's disease. J Ophthalmol 2017:2180723

47. Cheng $D$ et al (2018) Inner retinal microvasculature damage correlates with outer retinal disruption during remission in Behcet's posterior uveitis by optical coherence tomography angiography. Invest Ophthalmol Vis Sci 59(3):1295-1304

48. Emre $S$ et al (2019) Optical coherence tomography angiography findings in Behcet patients. Int Ophthalmol. https://doi.org/10.1007/s10792-019-01080-1

49. Raafat KA, Allam R, Medhat BM (2018) Optical coherence tomography angiography findings in patients with nonocular Behcet disease. Retina [Epub ahead of print]

50. Cerquaglia A et al (2018) New insights on ocular sarcoidosis: an optical coherence tomography angiography study. Ocul Immunol Inflamm 1-10. https://doi.org/10.1080/09273948.2018.1497665

51. Aggarwal K et al (2018) The role of optical coherence tomography angiography in the diagnosis and management of acute Vogt-KoyanagiHarada disease. Ocul Immunol Inflamm 26(1):142-153

52. Aggarwal K, Agarwal A, Gupta V (2018) Type 2 choroidal neovascularization in a choroidal granuloma detected using swept-source optical coherence tomography angiography. Ophthalmic Surg Lasers Imaging Retina 49(7):534-539

53. Aggarwal $\mathrm{K}$ et al (2018) Detection of type 1 choroidal neovascular membranes using optical coherence tomography angiography in tubercular posterior uveitis. Retina [Epub ahead of print]

54. Cheng $L$ et al (2016) Spectral-domain optical coherence tomography angiography findings in multifocal choroiditis with active lesions. Am J Ophthalmol 169:145-161

55. Zahid S et al (2017) Optical coherence tomography angiography of chorioretinal lesions due to idiopathic multifocal choroiditis. Retina 37(8):1451-1463

56. Astroz P et al (2018) Optical coherence tomography angiography to distinguish choroidal neovascularization from macular inflammatory lesions in multifocal choroiditis. Retina 38(2):299-309
57. Levison AL et al (2017) Choroidal neovascularisation on optical coherence tomography angiography in punctate inner choroidopathy and multifocal choroiditis. Br J Ophthalmol 101(5):616-622

58. Waizel $\mathrm{M}$ et al (2018) Superficial and deep retinal foveal avascular zone OCTA findings of non-infectious anterior and posterior uveitis. Graefes Arch Clin Exp Ophthalmol 256(10):1977-1984

59. Maier $\mathrm{M}$ et al OCT angiography findings in acute posterior multifocal placoid pigment epitheliopathy (APMPPE)(2017) Ophthalmologe 114(1):60-65

60. Mangeon M et al (2017) Multimodal evaluation of patients with acute posterior multifocal placoid pigment epitheliopathy and serpiginous choroiditis. Ocul Immunol Inflamm 26(8):1-7

61. Werner JU et al (2017) Multi-modal imaging including optical coherence tomography angiography in patients with posterior multifocal placoid pigment epitheliopathy. Ophthalmic Surg Lasers Imaging Retina 48(9):727-733

62. Salvatore $S$ et al (2016) Multimodal imaging in acute posterior multifocal placoid pigment epitheliopathy demonstrating obstruction of the choriocapillaris. Ophthalmic Surg Lasers Imaging Retina 47(7): $677-681$

63. Dolz-Marco R et al (2017) Optical coherence tomography angiography shows inner choroidal ischemia in acute posterior multifocal placoid pigment epitheliopathy. Retin Cases Brief Rep 11(Suppl 1):S136-S143

64. El Ameen A, Herbort CP Jr (2016) Serpiginous choroiditis imaged by optical coherence tomography angiography. Retin Cases Brief Rep 12(4):279-285

65. Pakzad-Vaezi K et al (2018) Swept-source OCT angiography of serpiginous choroiditis. Ophthalmol Retina 2(7):712-719

66. Montorio D et al (2017) Swept-source optical coherence tomography angiography in serpiginous choroiditis. Br J Ophthalmol 102(7):991-995

67. Pichi F et al (2016) En face optical coherence tomography and optical coherence tomography angiography of multiple evanescent white dot syndrome: new insights into pathogenesis. Retina 36(Suppl 1):S178-S188

68. Yannuzzi NA et al (2017) Swept-source OCT angiography shows sparing of the choriocapillaris in multiple evanescent white dot syndrome. Ophthalmic Surg Lasers Imaging Retina 48(1):69-74

69. Pereira F et al (2018) Swept-source OCT in patients with multiple evanescent white dot syndrome. J Ophthalmic Inflamm Infect 8(1):16

70. Wang JC et al (2017) Distinguishing white dot syndromes with patterns of choroidal hypoperfusion on optical coherence tomography angiography. Ophthalmic Surg Lasers Imaging Retina 48(8):638-646

71. Lages $V$ et al (2018) MEWDS is a true primary choriocapillaritis and basic mechanisms do not seem to differ from other choriocapillaritis entities. J Curr Ophthalmol 30(4):281-286

72. Cerquaglia A et al (2017) Deep inside multifocal choroiditis: an optical coherence tomography angiography approach. Int Ophthalmol 37(4): 1047-1051

73. Nakao S et al (2016) Optical coherence tomography angiography for detecting choroidal neovascularization secondary to punctate inner choroidopathy. Ophthalmic Surg Lasers Imaging Retina 47(12):1157-1161

74. Liu TYA, Zhang AY, Wenick A (2018) Evolution of choroidal neovascularization due to presumed ocular histoplasmosis syndrome on multimodal imaging including optical coherence tomography angiography. Case Rep Ophthalmol Med. 2018;2018:5. https://doi.org/10.1155/2018/4098419

75. de Carlo TE et al (2015) Retinal and choroidal vasculature in birdshot chorioretinopathy analyzed using spectral domain optical coherence tomography angiography. Retina 35(11):2392-2399

76. Phasukkijwatana N, lafe N, Sarraf D (2017) Optical coherence tomography angiography of A29 birdshot chorioretinopathy complicated by retinal neovascularization. Retin Cases Brief Rep 11(Suppl 1):S68-S72

77. Pepple KL et al (2018) Use of en face swept-source optical coherence tomography angiography in identifying choroidal flow voids in 3 patients with birdshot chorioretinopathy. JAMA Ophthalmol 136(11):1288-1292

78. Casalino G et al (2018) Acute macular neuroretinopathy: pathogenetic insights from optical coherence tomography angiography. Br J Ophthalmol 103(3):410-414

79. Nemiroff $J$ et al (2018) Optical coherence tomography angiography of acute macular neuroretinopathy reveals deep capillary ischemia. Retin Cases Brief Rep 12(Suppl 1):S12-s15

80. Thanos A et al (2016) Optical coherence tomographic angiography in acute macular neuroretinopathy. JAMA Ophthalmol 134(11):1310-1314

81. Lee SY et al (2017) Choroidal features of acute macular neuroretinopathy via optical coherence tomography angiography and correlation with serial multimodal imaging. JAMA Ophthalmol 135(11):1177-1183 
82. Pecen PE, Smith AG, Ehlers JP (2015) Optical coherence tomography angiography of acute macular neuroretinopathy and paracentral acute middle maculopathy. JAMA Ophthalmol 133(12):1478-1480

83. Del Porto L, Petzold A (2017) Optical coherence tomography angiography and retinal microvascular ramification in acute macular neuroretinopathy and paracentral acute middle maculopathy. Surv Ophthalmol 62(3):387-389

84. Chu S et al (2018) Projection-resolved OCT angiography of microvascular changes in paracentral acute middle maculopathy and acute macular neuroretinopathy. Invest Ophthalmol Vis Sci 59(7):2913-2922

85. Kulikov AN, Maltsev DS, Leongardt TA (2018) Retinal microvasculature alteration in paracentral acute middle maculopathy and acute macular neuroretinopathy: a quantitative optical coherence tomography angiography study. Retin Cases Brief Rep [Epub ahead of print]

86. Pichi F et al (2018) Cilioretinal artery hypoperfusion and its association with paracentral acute middle maculopathy. Br J Ophthalmol. https://doi.org/10. 1136/bjophthalmol-2018-312774

87. Mehrotra N et al (2018) Panoramic optical coherence tomography angiography features in acute zonal occult outer retinopathy. Indian J Ophthalmol 66(12):1856-1858

88. Naik AU, Ezhilvathani N, Biswas J (2018) Acute zonal occult outer retinopathy: is optical coherence tomography angiography useful? Indian J Ophthalmol 66(11):1637-1639

89. Agarwal A et al (2017) Multimodal imaging in ocular tuberculosis. Ocul Immunol Inflamm 25(1):134-145

90. Yee HY et al (2016) Optical coherence tomography angiography of choroidal neovascularization associated with tuberculous serpiginous-like choroiditis. Ocul Immunol Inflamm 24(6):699-701

91. Agarwal A et al (2016) Optical coherence tomography angiography features of paradoxical worsening in tubercular multifocal serpiginoid choroiditis. Ocul Immunol Inflamm 24(6):621-630

92. Wang $\mathrm{H}$ et al (2018) Multimodal evaluation of presumed tuberculous serpiginous-like choroiditis. Ocul Immunol Inflamm. https://doi.org/10.1080/ 09273948.2018 .1501497

93. Nagpal M et al (2018) Correlation of "panoramic" optical coherence tomography angiography with indocyanine green angiography characteristics of serpiginous-like choroiditis. Ophthalmic Surg Lasers Imaging Retina 49(11):859-869

94. Turkcu FM et al (2017) OCTA imaging of choroidal Neovascular membrane secondary to toxoplasma retinochoroiditis. Ophthalmic Surg Lasers Imaging Retina 48(6):509-511

95. Spaide RF (2015) Volume rendering of optical coherence tomography angiography reveals extensive retinal vascular contributions to neovascularization in ocular toxoplasmosis. Retina 35(11):2421-2422

96. Vezzola D et al (2018) Swept-source optical coherence tomography and optical coherence tomography angiography in acquired toxoplasmic chorioretinitis: a case report. J Med Case Rep 12(1):358

97. Costa de Andrade G et al (2018) Optical coherence tomography angiography findings in acute retinal necrosis. Retin Cases Brief Rep [Epub ahead of print]

98. Agarwal A, Aggarwal K, Gupta V (2018) Infectious uveitis: an Asian perspective. Eye (Lond) 33(1):50-65

99. Tavassoli S et al (2016) Optical coherence tomography angiography findings in dengue-related maculopathy: a case report. Ophthalmic Surg Lasers Imaging Retina 47(11):1057-1060

100. Aggarwal K et al (2017) Optical coherence tomography angiography features of acute macular neuroretinopathy in dengue fever. Indian J Ophthalmol 65(11):1235-1238

101. Pichi F et al (2016) A focal chorioretinal bartonella lesion analyzed by optical coherence tomography angiography. Ophthalmic Surg Lasers Imaging Retina 47(6):585-588

\section{Submit your manuscript to a SpringerOpen ${ }^{\circ}$ journal and benefit from:}

- Convenient online submission

- Rigorous peer review

- Open access: articles freely available online

- High visibility within the field

- Retaining the copyright to your article

Submit your next manuscript at $\boldsymbol{\nabla}$ springeropen.com 